Revised Manuscript to Appl. Catal. B:Environ.

\title{
Ti-incorporated SBA-15 mesoporous silica as an efficient and robust Lewis solid acid catalyst for the production of high-quality biodiesel fuels
}

Shih-Yuan Chen, ${ }^{*}$ Takehisa Mochizuki, Yohko Abe, Makoto Toba, Yuji Yoshimura

Hydrotreating Catalysis Team, Research Center for New Fuels and Vehicle Technology, National Institute of Advanced Industrial Science and Technology (AIST), 1-1-1

Higashi, Tsukuba, Ibaraki 305-8565, Japan.

To whom correspondence should be addressed:

Shih-Yuan Chen, Ph.D.

Researcher,

Hydrotreating Catalysis Team, Research Center for New Fuels and Vehicle Technology, National Institute of Advanced Industrial Science and Technology (AIST), 1-1-1 Higashi, Tsukuba, Ibaraki 305-8565, Japan.

TEL: +81-29-861-2680

FAX: +81-29-861-4532

E-mail: sy-chen@aist.go.jp 


\begin{abstract}
One-pot synthesized Ti-SBA-15 mesoporous materials with various Ti loadings of 0.808-6.78 mol\% were applied as heterogeneous solid acid catalysts for simultaneous esterification and transesterification of vegetable oils with methanol into high-quality biodiesel fuel (BDF) at $200{ }^{\circ} \mathrm{C}$ under autogeneous pressure. According to the diffuse-reflectance (DR) UV-Vis spectra, diffuse-reflectance infrared Fourier transform (DRIFT) spectra and pulsed ammonia $\left(\mathrm{NH}_{3}\right)$ chemisorption studies combined with other conventional characterizations, the catalytically active site for high-quality BDF synthesis was mostly related to the tetrahedral $\mathrm{Ti}^{4+}$ species with weak Lewis acid character, which differential heat of $\mathrm{NH}_{3}$ adsorption was lower than $90 \mathrm{~kJ} \mathrm{mmol}^{-1}$. Due to that the tetrahedral $\mathrm{Ti}^{4+}$ species were accessible on largely mesoporous framework, the Ti-SBA-15 catalyst gave much higher activity in transesterification of crude Jatropha oil (CJO) with methanol than microporous titanosilicate of TS-1 and commercial $\mathrm{TiO}_{2}$ nanocrystallites. Among them, the $3 \mathrm{Ti}-\mathrm{SBA}-15$ catalyst with a $\mathrm{Ti}$ loading of $2.46 \mathrm{~mol} \%$ showed a highest fatty acid methyl ester (FAME) content of 90 mass $\%$ at $200{ }^{\circ} \mathrm{C}$ for $3 \mathrm{~h}$ using a methanol-to-oil molar ratio of 27. When the reaction period and methanol-to-oil molar ratio were increased to 3-6 $\mathrm{h}$ and 108 , respectively, a great variety of edible and non-edible vegetable oils with various acid values (0.06-190
\end{abstract}


$\mathrm{mg} \mathrm{KOH} \mathrm{g}{ }^{-1}$ ), including refined soybean oil (RSO), refined rapeseed oil (RRO), waste cooking oil (WCO), crude palm oil (CPO), CJO and palm fatty acid distillates (PFAD), was directly transformed into high-quality BDFs, which met with a European standard (EN 14214:2009), over 3Ti-SBA-15 catalyst at $200{ }^{\circ} \mathrm{C}$. The used 3Ti-SBA-15 catalyst was easily regenerated by calcination and its high activity was maintained. Most importantly, the 3Ti-SBA-15 catalysts could resist $5 \mathrm{wt} \%$ of water or $30 \mathrm{wt} \%$ of free fatty acid (FFA), which tolerance levels were several ten times better than those of homogeneous and heterogeneous catalysts in the current BDF production technology.

Keywords: Biodiesel, non-edible vegetable oils, titanium, mesoporous silica, water and FFA resistances, Lewis solid acid. 


\section{Introduction}

BDF which mainly consists of FAME is considered as a sustainable bio-fuel for transportation sector due to lower emitting of green house gases, such as carbon dioxide and methane, and hazardous exhaust gases, such as sulfur oxides and nitrogen oxides, in comparison to burning petro-diesel [1]. Conventional BDF is synthesized by transesterification of high-grade vegetable oils with excess amounts of dehydrated methanol catalyzed by homogeneous alkali bases, such as $\mathrm{NaOH}, \mathrm{KOH}$ or $\mathrm{NaOCH}_{3}$, at mild reaction condition of around $60-80{ }^{\circ} \mathrm{C}$ and 1 bar [2-5]. To synthesize high-quality BDF with diminishing waste water and catalysts, the French Institute of Petroleum (IFP) have commercialized several Esterfip-H plants in European union using a heterogeneous base of zinc aluminate mixed oxide under severe reaction condition of $170-230{ }^{\circ} \mathrm{C}$ and $10-60$ bar [6,7]. Due to that FFA and water easily cause saponification and catalyst deactivation, only high-grade vegetable oils, such as refined soybean, rapeseed, palm and coconut oils, can be fed in base-catalyzed transesterification, where the upper limits of FFA and water contents are $0.5 \mathrm{wt} \%$ and $0.3 \mathrm{wt} \%$, respectively. Besides high production cost, recent reports argued that BDF made by edible vegetable oils might not be sustainable enough to be used in European Union [8,9]. Furthermore, 
the increased demand for planting and irrigation may destroy tropical rainforest, namely the main carbon reducer in earth, and make a significant increase in water and nitrogen fertilizer use, yielding plenty of edible vegetable oils [10].

On purpose of reducing production cost, pressure on environment, and competition for food supply, recent studies have focused on efficient and economical way to transform non-edible vegetable oils, WCO and animal fats with high FFA and water contents into high-quality BDFs [2-7, 11-17]. For example, Jatropha curcas can be grown on dry areas without careful irrigation and its seeds contain around $25-30 \mathrm{wt} \%$ of non-edible Jatropha oil with high FFA content up to $15 \mathrm{wt} \%$ [5]. It is generally agreed that Jatropha BDF has a little impact on food supply and environment. However, the removal of a large amount of FFA from CJO or other low-grade feedstock is essential for minimizing the formation of unwanted soap, which makes separation and purification a difficult task. The current way is to pre-esterify FFA of low-grade feedstock catalyzed by liquid acids, such as sulfuric acid or para-toluenesulfonic acid, before based-catalyzed transesterification, [16]. Unfortunately, liquid acid and base catalysts are corrosive and difficult to be recycled. The production cost is greatly increased by the complicated processing steps and costly anticorrosive facilities. Large amounts of waste catalysts and water are formed, which have seriously polluted our 
environment. The life times of vehicle's engine and exhaust system are likely shortened by burning alkali- and acid-contaminated BDF products. Numerous reports have studied solid acid catalysts for simultaneous esterification and transesterification [18-21]. However, the solid acid-catalyzed BDF production process is mostly carried out at severe condition using excess amounts of catalyst and methanol because of slow reaction rate. Macario and Giordano lately indicated that Amberlyst-15 acidic resin was active in esterification of FFA feed into BDF but it was quite poor in transesterification of triglycerides (TG) [18]. Albe-Rubio et al. further reported that the sulfonic acid-functionalized mesoporous silica was deactivated due to leaching of active phases and deposition of organic species during BDF synthesis [19]. To overcome these drawbacks, the development of innovative solid acid catalysts for simultaneous esterification and transterification of a great diversity of low-grade feedstock with high acid value at moderate condition has been an emergent and challenge field of research.

Ti-incorporated porous silica materials, particularly MFI- and MWW-type titanosilicates, have been industrially applied as green solid catalysts in clean synthesis of fine chemicals through selective oxidation, hydroxylation and ammoxidation [22-32]. In contrast, only limited numbers of studies have dealt with BDF production technology because the Ti-based catalysts have been regarded to be poor in acid-catalyzed reactions 
[33-37]. Oku et al. showed that TS-1 and Ti-impregnated amorphous silica gave ca. 74-79 mol\% of FAME yield in transesterification of triolein with subcritrical methanol at $200{ }^{\circ} \mathrm{C}$ and 60 bar $[33,34]$. However, Siano et al. reported that only 59-64\% of refined soybean oil were transesterified with methanol into FAME catalyzed by Ti-grafted amorphous silica at $180{ }^{\circ} \mathrm{C}$ under autogenous pressure [35-37]. In addition to serious leaching of Ti species, the FAME yields dropped ca. $27 \%$ and $20 \%$ by adding 5 $w t \%$ of FFA and $0.5 \mathrm{wt} \%$ of water to the reaction mixtures, respectively. There is still room for improving the activity and reusability of Ti-containing catalysts with high water and FFA tolerance levels in high-quality BDF synthesis. In a short communication, we lately demonstrated that the synthesis of high-quality BDF can be carried out over Ti-containing catalysts at $200{ }^{\circ} \mathrm{C}$ under autogeneous pressure [38]. Herein a detailed study on the application of mesoporous Ti-SBA-15 materials as weak Lewis solid acid catalysts in synthesis of high-quality BDFs derived from a great variety of non-edible and edible vegetable oils property was presented, in comparison to mesoporous silica of SBA-15, micrporous aluminasilicate of H-ZSM-5, microporous titanosilicate of TS-1 and commercial $\mathrm{TiO}_{2}$ nanocrystallites as reference catalysts. The influences of structural property and acidic nature on the catalytic performance and the water and FFA tolerance levels were particularly reported. The reaction mechanism of 
high-quality BDF synthesis over Ti-SBA-15 catalysts was proposed.

\section{Experimental}

\subsection{Synthesis of titanium oxychloride}

Titanium oxychloride was freshly prepared by carefully mixing of titanium tetraisopropoxide (TTIP, Wako) and hydrochloric acid ( $\mathrm{HCl}$, Wako), where the $\mathrm{HCl} / \mathrm{TTIP}$ molar ratio can be varied in the range of 1.5-30 [31,38]. Typically, $14.8 \mathrm{~g}$ (0.052 mol) of TTIP was dropwisely added to $12.7 \mathrm{~g}(0.13 \mathrm{~mol})$ of conc. $\mathrm{HCl}$ solution at $0{ }^{\circ} \mathrm{C}$ under vigorously stirring, where the $\mathrm{HCl} / \mathrm{TTIP}$ molar ratio was 2.5 . The freshly prepared titanium oxychloride was transparent yellowish solution.

\subsection{One-pot synthesis of Ti-SBA-15 catalysts}

One-pot synthesized Ti-SBA-15 catalysts with various Ti loadings were prepared by co-condensation of tetraethyl orthosilicate (TEOS, Strem Chemicals) and titanium oxychloride using Pluronic P123 triblock copolymer $(M n=5800$, Aldrich $)$ as 
pore-directing agent in the self-generated acidic environment with the aid of sodium chloride $(\mathrm{NaCl}, \mathrm{Wako})[31,38]$. The gel compositions were varied in 0.0087-0.22 P123: 1 TEOS: 0.010-0.10 TTIP: 0.015-3.0 HCl: 0-6 NaCl: $220 \mathrm{H}_{2} \mathrm{O}$. Typically, $3.0 \mathrm{~g}$ of P123 and $2.36 \mathrm{~g}$ of $\mathrm{NaCl}$ were thoroughly dissolved in $160 \mathrm{~g}$ of distilled water at $35{ }^{\circ} \mathrm{C}$. To this solution, $8.4 \mathrm{~g}$ of TEOS and various amounts of titanium oxychloride (1-10 mol\% of Si) were simultaneously added under stirring. The synthesis gels sealed in the polypropylene (PP) bottle were stirred at $35{ }^{\circ} \mathrm{C}$ for $24 \mathrm{~h}$ and then hydrothermally treated at $100{ }^{\circ} \mathrm{C}$ for another $24 \mathrm{~h}$ under a static condition. The white precipitates collected by filtering and washing with distilled water were dried at $100{ }^{\circ} \mathrm{C}$ overnight. P123 was removed by calcining the as-made materials at $500{ }^{\circ} \mathrm{C}$ for $12 \mathrm{~h}$ in air. As a result, the xTi-SBA-15 catalysts were obtained, where $\mathrm{x}$ was the Ti/Si molar percentages in the gels.

\subsection{Reference catalysts}

Siliceous SBA-15 was prepared by the procedures described by Zhao et al. [39]. Typically, $8.4 \mathrm{~g}$ of TEOS was added to $160 \mathrm{~mL}$ of $2 \mathrm{M} \mathrm{HCl}$ synthesis solution containing $4.0 \mathrm{~g}$ of P123 under stirring. The gel composition was 0.017 P123: 1 TEOS: 
$7.94 \mathrm{HCl}: 221 \mathrm{H}_{2} \mathrm{O}$. The synthesis gel sealed in PP bottle was stirred at $35{ }^{\circ} \mathrm{C}$ for $24 \mathrm{~h}$, and then hydrothermally treated at $100{ }^{\circ} \mathrm{C}$ steadily for another $24 \mathrm{~h}$. The white precipitate collected by filtration, washing and drying at $100{ }^{\circ} \mathrm{C}$ was calcined at $500{ }^{\circ} \mathrm{C}$ to remove P123 template. As a result, siliceous SBA-15 was obtained.

A sodium-form ZSM-5 (Na-ZSM-5, item No. HSZ820NAA) with a surface area of $322 \mathrm{~m}^{2} / \mathrm{g}$ and a $\mathrm{Na}_{2} \mathrm{O}$ content of 3.7 , and $\mathrm{a}_{2} \mathrm{O}_{3} / \mathrm{SiO}_{2}$ ratio of 23.2 was purchased from Tosoh Co., Ltd. Before used, $1.0 \mathrm{~g}$ of Na-ZSM-5 was ion-exchanged with $100 \mathrm{~mL}$ of 1 $\mathrm{M} \mathrm{NH}_{4} \mathrm{NO}_{3}$ for three times, followed by calcining at $550{ }^{\circ} \mathrm{C}$ for $3 \mathrm{~h}$ in air after washing with a proper amount of de-ionized water and drying at $100{ }^{\circ} \mathrm{C}$ overnight. As a result, the proton-form ZSM-5 (H-ZSM-5) was obtained.

A titanosilicalite-1 (TS-1, item No. ARC-TS-1CL(1)) with a surface area of 390 $\mathrm{m}^{2} / \mathrm{g}$ and a $\mathrm{SiO}_{2} / \mathrm{TiO}_{2}$ molar ratio of 35 was supplied by Catalysis Society of Japan and used as received.

The titanium dioxide $\left(\mathrm{TiO}_{2}\right.$, item No. JRC-TIO-2) with a surface area of $18 \mathrm{~m}^{2} / \mathrm{g}$ and an anatase size of $84.7 \mathrm{~nm}$ supplied by Catalysis Society of Japan was designated as $\mathrm{TiO}_{2}$-L. Another $\mathrm{TiO}_{2}$ with a surface area of $128 \mathrm{~m}^{2} / \mathrm{g}$ and an anatase size of $25.5 \mathrm{~nm}$ supplied by JGC Catalysts and Chemicals Co., Ltd, was designated as $\mathrm{TiO}_{2}-\mathrm{M}$. The other extruded $\mathrm{TiO}_{2}$ (item No. 35E-105) with a surface area of $164 \mathrm{~m}^{2} / \mathrm{g}$ and an anatase 
size of $15.0 \mathrm{~nm}$ supplied by JGC Catalysts and Chemicals Co., Ltd, was designated as $\mathrm{TiO}_{2}-\mathrm{S}$. Three $\mathrm{TiO}_{2}$ nanocrystallites were used as received. Note that the $\mathrm{TiO}_{2}-\mathrm{S}$ and $\mathrm{TiO}_{2}-\mathrm{M}$ have similar features in DR UV-Vis and DRIFT spectra.

\subsection{Characterizations}

Powder X-ray diffraction (XRD) patterns were recorded by a Bruker AXS D8 advance diffractrometer with $\mathrm{Cu} \mathrm{K} \alpha$ radiation $(\lambda=1.5418 \AA$ ) operating at $40 \mathrm{kV}$ and 40 $\mathrm{mA}$. The $\mathrm{N}_{2}$ adsorption-desorption isotherms were measured by a BELSORP 28SA instrument (BEL Japan, Inc., Osaka) at $77 \mathrm{~K}$. Prior to the measurements, the calcined samples were degassed at $200{ }^{\circ} \mathrm{C}$ under vacuum $(<10 \mathrm{~Pa})$ for at least $200 \mathrm{~min}$. The specific surface area $\left(\mathrm{S}_{\mathrm{BET}}\right)$ was calculated by $\mathrm{BET}$ method in the $P / P_{0}$ region of 0.05- 0.25 . The total pore volume $\left(\mathrm{V}_{\text {Total }}\right)$ was accumulated up to $P / P_{0}$ of 0.95 . The pore size distribution (PSD) was analyzed by a modified BdB-FHH method using the adsorption profile and the pore diameter $(\Phi)$ was obtained from the peak positions of the PSD curves $[40,41]$. The element contents in bulk were analyzed by inductively coupled plasma-optic emission spectroscopy (ICP-OES) using a Thermo Scientific iCAP 6300 ICP spectrometer. Thermogravimetry analysis (TGA) and different thermal 
analysis (DTA) were performed on a Rigaku ThermoPlusEvo2 TG8120 instrument with a ramping rate of $10{ }^{\circ} \mathrm{C} / \mathrm{min}$ and an air flow of $100 \mathrm{~mL} / \mathrm{min}$. The DR UV-Vis spectra were recorded by a JASCO V-570 spectrometer equipped with an integrating sphere detector. Barium sulfate was used as reference material. The DRIFT spectra of Ti-SBA-15 and reference catalysts before and after pyridine adsorption were recorded by a Thermo Nicolet Nexus 870 FT-IR instrument equipped with smart collector of in situ DRIFT cell at $100-500{ }^{\circ} \mathrm{C}$ under He flow. Prior to the measurement, the calcined samples $(20 \mathrm{mg})$ diluted with $\mathrm{KBr}\left(180 \mathrm{mg}\right.$, Acros) were pretreated at $500{ }^{\circ} \mathrm{C}$ for $1 \mathrm{~h}$ under He flow. The differential heats of $\mathrm{NH}_{3}$ adsorption on Ti-SBA-15 and reference catalysts were measured by a micro-calorimeter (CSA-450G, Tokyo Riko, Co. Ltd., Tokyo) at $50{ }^{\circ} \mathrm{C}$. The calcined samples (ca. $100-250 \mathrm{mg}$ ) were degassed at $300{ }^{\circ} \mathrm{C}$ for 2 $\mathrm{h}$ under high vacuum $\left(<10^{-5}\right.$ torr $)$ before the measurements.

\subsection{Physicochemical property and fatty acid (FA) profile of vegetable oils}

The physicochemical property and FA profile of various vegetable oils analyzed by a modified IUPAC method are tabulated in Table S1 (ESI) [42]. The acid values of various vegetable oils are $0.06-190 \mathrm{mg} \mathrm{KOH} / \mathrm{g}$, which decrease in the following order: 
$\mathrm{PEAD}>\mathrm{CJO}>\mathrm{CPO}>\mathrm{WCO}>\mathrm{RRO}>\mathrm{RSC}$. The molecular weights of various vegetable oils estimated by the FA profiles are between 830 and $892 \mathrm{~g} \mathrm{~mol}^{-1}$. PEAD mainly consisted of palmitic acid (16:0) has a lowest molecular weight whereas CJO containing large amounts of oleic acid (18:1) and linoleic acid (18:2) has highest molecular weight. Moreover, the amounts of unsaturated FA profiles of RSO, RRO, WCO and CJO are higher than those of CPO and PEAD.

\subsection{Synthesis of $B D F$}

The transesterification of various vegetable oils with methanol over Ti-SBA-15 and reference catalysts was carried out by a high-pressure batch-type stainless steel reactor $(1.8 \mathrm{~mm}$ in internal diameter and $30 \mathrm{~cm}$ in length) lined with a glass tube $(1.5$ $\mathrm{mm}$ in internal diameter and $26 \mathrm{~cm}$ in length) heating by an electric furnace under a constant vibration frequency. Prior to the reactions, the catalysts were dried at $110{ }^{\circ} \mathrm{C}$. In the typical reaction, a $2.50 \mathrm{~g}(2.8 \mathrm{mmol})$ of CJO, $1.25-19.3 \mathrm{~g}(39.1-603 \mathrm{mmol})$ of anhydrous methanol and $0.375 \mathrm{~g}$ of dried catalyst were sealed in a glass-lined stainless steel reactor under $\mathrm{N}_{2}$ atmosphere. Note that the oxidation stability of BDF can be significantly decreased if the unsaturated bonds on the carbon chain of FAMEs are 
oxidized over Ti-based materials in air. The methanol/oil molar ratios were varied in the range of 14-216. The catalyst amount was kept at $15 \mathrm{wt} \%$ of CJO as well as other vegetable oils. Mixing effects can be ignored if the catalyst amount is lower than 25 wt $\%$ of CJO. To start the transesterification, the reactor was quickly inserted into a pre-heated electric furnace and then continuously shaken up and down with a constant speed of $28 \mathrm{rpm}$ at $200{ }^{\circ} \mathrm{C}$. After the transesterification, the reactor was quickly removed from the electronic furnace and then air-cooled to room temperature for around 15-20 min. The BDF products were obtained by removal of solid catalyst through a polytetrafluoroethylene (PTFT) syringe filter, evaporating methanol at $80{ }^{\circ} \mathrm{C}$ using a rotary vacuum evaporator, and then discarding the bottom layer of glycerol.

\subsection{Analysis of $B D F$}

The glycerol $(\mathrm{G})$ and glycerides contents were quantitatively analyzed by an Agilent $6890 \mathrm{~N}$ GC-FID instrument equipped with a DB-5HT column $(0.25 \mathrm{~mm}$ in diameter, $60 \mathrm{~m}$ in length, $1 \mu \mathrm{m}$ in thickness) based on the EN 14105 method, where 1,2,4-butanetriol was used as the internal standard for the determination of the free $\mathrm{G}$, 1,2,3-tricaproylglycerol was used as another internal standard for the determination of 
the glycerides (mono-, di- and tri-) and N,O-bis(trimethylsilyl)-trifluoroacetamide (BSTFA, TCI) was used as silylation agent. The percentage of total glycerol $\left(\mathrm{G}_{\mathrm{T}}\right)$ in BDF products is given by:

$\mathrm{G}_{\mathrm{T}}=\mathrm{G}+0.255 \mathrm{MG}+0.146 \mathrm{DG}+0.103 \mathrm{TG}$

Where G, MG, DG and TG are the percentages of glycerol, monoglycerides, diglycerides and triglycerides in BDF products, respectively.

The FAME and FFA contents were quantitatively analyzed by an Agilent $6890 \mathrm{~N}$ GC-FID instrument equipped with a HP-1 column $(0.32 \mathrm{~mm}$ in diameter, $60 \mathrm{~m}$ in length, $1 \mu \mathrm{m}$ in thickness) based on the EN 14103 method, where methyl heptadecanoate was used as internal standard and BSTFA was used as silylated agent. The percentage of FAME and FFA contents in BDF products are calculated by:

$$
\left.\mathrm{C} x=\left(\left(\sum \mathrm{A}_{\text {total }}\right) / \mathrm{A}_{\mathrm{mp}}\right) \times\left(\mathrm{C}_{\mathrm{mp}} \times \mathrm{V}_{\mathrm{mp}}\right) /(\mathrm{m})\right)
$$

Where, $\mathrm{C}_{x}$ is the FAME (or FFA) content, $\sum \mathrm{A}_{\text {total }}$ is the total peak area from the FAME in $\mathrm{C}_{12}$ to that in $\mathrm{C}_{24}$ (or from the FFA in $\mathrm{C}_{16}$ to that in $\mathrm{C}_{20}$ ), $\mathrm{A}_{\mathrm{mp}}$ is the peak area of methyl heptadecanoate, $\mathrm{C}_{\mathrm{mp}}$ is the concentration, in $\mathrm{mg} / \mathrm{mL}$, of the methyl heptadecanoate solution being used, $\mathrm{V}_{\mathrm{mp}}$ is the volume, in $\mathrm{mL}$, of the methyl 
heptadecanoate solution being used, and $\mathrm{m}$ is the mass, in $\mathrm{mg}$, of the sample.

\section{Results and Discussion}

\subsection{Catalyst characterization}

Fig. 1 shows the small- and wide-angle XRD patterns of Ti-SBA-15 and reference catalysts. In the small-angle region, the siliceous SBA-15 and Ti-SBA-15 catalysts with different $\mathrm{Ti}$ loadings have three distinct diffraction peaks at $2 \theta=0.8-2.0^{\circ}$, corresponding to the (100), (110) and (200) planes of well-ordered p6mm structure in the sequence from left to right [39]. It indicates that Ti incorporated in Ti-SBA-15 catalysts has a little influence on pore ordering. In the wide-angle region, the siliceous SBA-15 and Ti-SBA-15 catalysts have a characteristic band at $2 \theta=15-35^{\circ}$, attributed to amorphous silica framework. The 10Ti-SBA-15 catalyst has a weak diffraction peak at $2 \theta=25.5^{\circ}$, indexed as the (101) plane of anatase $\mathrm{TiO}_{2}$ with a size of $6.3 \mathrm{~nm}$ determined by Scherrer equation with the peak width at half-maximum height. This result suggests that $\mathrm{Ti}$ in one-pot synthesized Ti-SBA-15 is X-ray amorphous species only if the Ti/Si molar ratios in the gels are equal to or smaller than $5.83 \mathrm{~mol} \%$. 
As to the reference catalysts, the wide-angle XRD patterns show that three $\mathrm{TiO}_{2}-\mathrm{S}$, $\mathrm{TiO}_{2}-\mathrm{M}$ and $\mathrm{TiO}_{2}-\mathrm{L}$ catalysts are crystallized in anatase phase with different sizes of 15.0, 25.5 and $84.7 \mathrm{~nm}$, respectively. The zeolitic MFI frameworks of microporous H-ZSM-5 and TS-1 materials are confirmed by the XRD patterns and in good agreement on the literature reports $[22,23]$.

The structural property and porosity of Ti-SBA-15 and reference catalysts are studied by $\mathrm{N}_{2}$ physisorption technique. Fig. 2 shows that the siliceous SBA-15 and Ti-SBA-15 catalysts contain a classic type IV isotherm with a steep $\mathrm{H}_{1}$ hysteresis loop at high $P / P_{0}$ region of $0.55-0.80$, indicating the presence of well-ordering channeling pores with narrow PSDs. The hysteresis loop slight shifts toward relatively low $P / P_{0}$ region as the $\mathrm{Ti} / \mathrm{Si}$ molar ratios in the gels are increased. It suggests that the pore sizes are slightly decreased by Ti incorporated in Ti-SBA-15 catalysts. Regarding to three $\mathrm{TiO}_{2}$ catalysts, the hysteresis loops widely cover at $P / P_{0}$ region higher than 0.80 , which is attributed to the intra-aggregate voids of anatase nanocrystallites. On the other hand, the H-ZSM-5 and TS-1 catalysts have a classical type I isotherm without apparent hysteresis loops, corresponding to the $\mathrm{N}_{2}$ adsorbed in and desorbed from microporous zeolitic framework. A small and flat hysteresis loop is seen in H-ZSM-5 at relatively wide $P / P_{0}$ region of $0.40-0.90$, indicating the presence of a few slit-shaped pores as 
defect structure.

Table 1 shows the textural properties of Ti-SBA-15 and reference catalysts. The $\mathrm{S}_{\mathrm{BET}}, \mathrm{V}_{\mathrm{p}}$ and $\Phi$ values of siliceous SBA-15 are $914 \mathrm{~m}^{2} \mathrm{~g}^{-1}, 1.1 \mathrm{~cm}^{3} \mathrm{~g}^{-1}$ and $7.5 \mathrm{~nm}$, respectively, which are akin to the literature report [39]. As to the Ti-SBA-15 catalysts, the $\mathrm{S}_{\mathrm{BET}}, \mathrm{V}_{\mathrm{p}}$ and $\Phi$ values are varied in the range of $677-811 \mathrm{~m}^{2} \mathrm{~g}^{-1}, 0.80-0.96 \mathrm{~cm}^{3} \mathrm{~g}-1$ and 7.1-7.9 nm, respectively, slightly decreased with the increasing of the Ti loadings due to the formation of extra-framework Ti clusters or anatase $\mathrm{TiO}_{2}$ nanocrystallites. Three $\mathrm{TiO}_{2}$ catalysts have low $\mathrm{S}_{\mathrm{BET}}$ and $\mathrm{V}_{\mathrm{p}}$ values of $11-164 \mathrm{~m}^{2} \mathrm{~g}^{-1}$ and $0.10-0.38 \mathrm{~cm}^{3}$ $\mathrm{g}^{-1}$, increased with the decreasing of anatase sizes, whereas the $\Phi$ values in $15.0-84.7$ nm have an opposite trend. The H-ZSM- 5 and TS- 1 catalysts possess medium $\mathrm{S}_{\mathrm{BET}}$ and $\mathrm{V}_{\mathrm{p}}$ values of 343-405 $\mathrm{m}^{2} \mathrm{~g}^{-1}$ and $0.23-0.27 \mathrm{~cm}^{3} \mathrm{~g}^{-1}$, respectively, and very small micropores $(\sim 0.56 \mathrm{~nm})$.

The TGA technique has been utilized to probe the interaction of surfactants and inorganic pore walls in mesoporous materials [43-46]. Fig. 3 shows that siliceous SBA-15 contains a single weight loss $(49.8 \mathrm{wt} \%)$ in $130-250{ }^{\circ} \mathrm{C}$, corresponding to decomposition of P123 copolymer uniformly interacted with siliceous pore walls, and the peak maximum of the DTA profile is around $182{ }^{\circ} \mathrm{C}$. These data are consistent with the previous report [39]. Regarding to the Ti-SBA-15 catalysts, the weight losses of 
P123 copolymer are varied in 41.0-54.8 $\mathrm{wt} \%$, decreased with the increasing of the $\mathrm{Ti}$ loadings. Meanwhile, the DTA peak corresponding to the P123 decomposition gradually shifts to $252-298{ }^{\circ} \mathrm{C}$ with diminishing of the original peak centered at $180-213$ ${ }^{\circ} \mathrm{C}$. The peak centered at $180-213{ }^{\circ} \mathrm{C}$ is assigned to the decomposition of $\mathrm{P} 123$ copolymer interacted with the siliceous pore walls and the other peak centered at 252-298 ${ }^{\circ} \mathrm{C}$ should have to do with decomposition of P123 copolymer interacted with the superficial Ti species close to the pore surfaces.

Siliceous SBA-15 is self-assembled through a cooperative self-assembly mechanism driven by an electrostatic $\left(\mathrm{S}^{0} \mathrm{H}^{+}\right)\left(\mathrm{Cl}^{-} \mathrm{I}^{+}\right)$interaction, where the $\mathrm{P} 123$ micelles $\left(\mathrm{S}^{0}\right)$ are surrounded with the protons $\left(\mathrm{H}^{+}\right)$, and the silicate species $\left(\mathrm{I}^{+}\right)$are surrounded with the chloride anions $\left(\mathrm{Cl}^{-}\right)[39,41,46]$. The decomposition of P123 copolymer enclosed by siliceous pore walls of SBA-15 is generally observed at around $180-200{ }^{\circ} \mathrm{C}$. When the Ti-SBA-15 catalysts were self-assembled, the white precipitates were formed from a few hours to ca. $50 \mathrm{~min}$ as the $\mathrm{Ti} / \mathrm{Si}$ molar ratios in the gels were increased from 0.01 to 0.1 . This phenomenon implies that the self-assembly rate of P123 micelles and TEOS is accelerated when titanium oxychloride precursors are sandwiched between them $[41,46]$. It is well-known that the inorganic ions can associate with hydrophilic polyethylene oxide chains of P123 micelles through weak coordination bond [47]. This 
interaction explains that the decomposition of $\mathrm{P} 123$ polymer coordinated with superficial $\mathrm{Ti}$ species rich on pore walls of Ti-SBA-15 shifts to relatively high temperature region of $252-298{ }^{\circ} \mathrm{C}$.

The chemical environment of Ti species in Ti-SBA-15 catalysts were investigated by DR UV-Vis spectra, in comparison to those of TS-1 and pure $\mathrm{TiO}_{2}$ reference catalysts. Fig. 4(A) shows that TS-1 has a narrow band centered at $215 \mathrm{~nm}$ and a weak shoulder centered at $250 \mathrm{~nm}$, which are associated to the metal charge transfer (LMCT) transition from $\mathrm{O}^{2-}$ to $\mathrm{Ti}^{4+}$ species in tetrahedral and octahedral coordination spheres, respectively [22-25]. The $\mathrm{TiO}_{2}-\mathrm{S}$ and $\mathrm{TiO}_{2}-\mathrm{L}$ catalysts show a very broad band centered at $320 \mathrm{~nm}$, which corresponds to the band gap transition of 3.2-3.3 eV, with two weak LMCT bands on the left shoulder. As to the Ti-SBA-15 catalysts, a band consisted of LMCT and band gap transitions is observed in relatively narrow range of 190-360 nm, indicating that the tetrahedral, octahedral and polymeric $\mathrm{Ti}^{4+}$ species are mixed in small domains. The band gaps are varied in 3.60-3.86 eV, blue-shifted in comparison to bulky anatase $\mathrm{TiO}_{2}$ due to the quantum size effect. Fig. 4(B) shows the relative peak areas of various $\mathrm{Ti}^{4+}$ species of Ti-SBA-15 and TS-1 catalysts by deconvolution of the DR UV-Vis spectra in Fig. 4(A). The LMCT bands of $\mathrm{O}^{2-}$ to $\mathrm{Ti}^{4+}$ species in tetrahedral and octahedral coordination spheres were fitted at 215 and $250 \mathrm{~nm}$, respectively. The band 
gap transition was varied in $290-305 \mathrm{~nm}$. For the TS-1 catalyst, the relative peaks areas of tetrahedral and octahedral $\mathrm{Ti}^{4+}$ species are $72 \%$ and $28 \%$, respectively, inferring that Ti is mostly incorporated in the zeolitic MFI framework. Regarding to the Ti-SBA-15 catalysts, the relative peak area of tetrahedral $\mathrm{Ti}^{4+}$ species is around $13-40 \%$, decreased linearly by increasing the Ti loadings, whereas those of octahedral $\mathrm{T}^{4+}$ species and band gap transition give an opposite trend.

The relative amounts of tetrahedral $\mathrm{Ti}^{4+}$ species in Ti-SBA-15 catalysts are estimated by multiplying the Ti loadings with relative peak areas of tetrahedral $\mathrm{Ti}^{4+}$ species in Fig. 4(B). The Ti loadings minus the relative amounts of tetrahedral $\mathrm{Ti}^{4+}$ species give the relative amounts of octahedral $\mathrm{Ti}^{4+}$ species in isolated and polymeric forms. The result shows that the tetrahedral $\mathrm{Ti}^{4+}$ species are linearly increased in Ti-SBA-15 catalysts with Ti loadings of $0.808-2.46 \mathrm{~mol} \%$ and the octahedral $\mathrm{Ti}^{4+}$ species give a similar trend (Fig. S1, ESI). When the Ti loadings range between 3.76 and $5.83 \mathrm{~mol} \%$, the amounts of tetrahedral $\mathrm{Ti}^{4+}$ species slightly raise to $0.97-1.15 \mathrm{~mol} \%$, which are close to the maximum loading of tetrahedral $\mathrm{T}^{4+}$ species in one-pot synthesized Ti-SBA-15 materials $[29,48]$. By contrast, the octahedral $\mathrm{Ti}^{4+}$ species are significantly increased to $2.79-4.68 \mathrm{~mol} \%$. When the Ti loading is further increased to $6.78 \mathrm{mo} \%$, the tetrahedral $\mathrm{Ti}^{4+}$ species decrease to $0.87 \mathrm{~mol} \%$, due to the formation of a 
large amount of octahedral $\mathrm{Ti}^{4+}$ species $(5.97 \mathrm{mo} \%)$.

The acidic strength of Ti-SBA-15 and reference catalysts was measured by differential heat of $\mathrm{NH}_{3}$ adsorption as a function of acid capacity at $50{ }^{\circ} \mathrm{C}$ (Fig. 5 and Table S2, ESI) [49,50]. The acid capacity decreases in the matter of H-ZSM-5 > 1-10Ti-SBA-15 $>$ SBA-15 $>$ TS- $1>\mathrm{TiO}_{2}-\mathrm{S}>\mathrm{TiO}_{2}-\mathrm{M}>\mathrm{TiO}_{2}-\mathrm{L}$. The acid strength is dependent on the chemical environments of acidic sites. The H-ZSM-5 catalyst with a high Al loading of $8.6 \mathrm{~mol} \%$ possesses a largest acid capacity of $2.83 \mathrm{mmol} \mathrm{g}$-cat $^{-1}$ widely distributed over various acid sites. The TS-1 catalyst with a Ti loading of 2.86

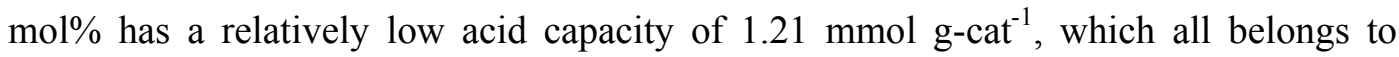
weakly acidic site. It can be said that the $\mathrm{Ti}^{4+}$ species in the MFI framework of TS-1 are less acidic than the $\mathrm{Al}^{3+}$ species in that of $\mathrm{H}-\mathrm{ZSM}-5$. Siliceous SBA-15 has an acid capacity of $1.65 \mathrm{mmol} \mathrm{g}_{\text {-cat }}{ }^{-1}$, associated with a large amount of surface silanol groups with weakly acidic nature. The acid capacities of Ti-SBA-15 catalysts are increased to 1.78-2.09 $\mathrm{NH}_{3}$ g-cat $^{-1}$, which mostly belong to weakly acidic sites and positively relate to the amount of tetrahedral $\mathrm{Ti}^{4+}$ species (Fig. S1, ESI). The acid capacity of 10Ti-SBA-15 catalyst is the lowest due to formation of anatase $\mathrm{TiO}_{2}$ nanocrystallites when incorporating such a high $\mathrm{Ti}$ loading. On the other hand, three $\mathrm{TiO}_{2}$ reference catalysts with different sizes of anatase phase have much lower acid capacity of 
0.115-0.704 mmol g-cat ${ }^{-1}$, which are positively related to surface areas and negatively related to crystalline sizes. Besides, the amounts of strongly and moderately acidic sites in $\mathrm{TiO}_{2}-\mathrm{M}$ and $\mathrm{TiO}_{2}-\mathrm{S}$ catalysts are higher than those of TS-1 and Ti-SBA-15 catalysts (Table S2, ESI). The strongly and moderately acidic sites in $\mathrm{TiO}_{2}$ nanocrystallites are probably derived from the coordinatively unsaturated $\mathrm{Ti}^{4+}$ species at surface defect sites. By contrast, the weakly acidic sites are mainly related to the tetrahedral $\mathrm{Ti}^{4+}$ species, which are rich in TS-1 and Ti-SBA-15 but poor in $\mathrm{TiO}_{2}$ nanocrystallites.

Fig. 6(A) shows the DRIFT spectra of pyridine adsorbed on 3Ti-SBA-15 catalyst at $100-400{ }^{\circ} \mathrm{C}$ under a He flow. The sharp $1445 \mathrm{~cm}^{-1}$ band and the weak $1540 \mathrm{~cm}^{-1}$ band are seen at $100-200{ }^{\circ} \mathrm{C}$ and gradually invisible at higher temperatures. It is evident that the 3Ti-SBA-15 catalyst has a majority of Lewis acid property, originated from the tetrahedral $\mathrm{Ti}^{4+}$ species in the mesoporous $\mathrm{SBA}-15$ framework [51,52]. Fig. 6(B) compares the DRIFT of pyridine adsorbed on various Ti-SBA-15 and reference catalysts recorded at $200{ }^{\circ} \mathrm{C}$. H-ZSM-5 shows a very strong band centered at $1445 \mathrm{~cm}^{-1}$, associated with pyridine coordinately bonded to the $\mathrm{Al}^{3+}$ species in the MFI framework as Lewis acid site, and a weak peak centered at $1540 \mathrm{~cm}^{-1}$, attributed to pyridinium ions probably formed by proton transfer from hydroxyl groups on the $\mathrm{Al}^{3+}$ species as Bronsted acid site. A moderate band centered at $1445 \mathrm{~cm}^{-1}$ and no evidence for a band 
at $1540 \mathrm{~cm}^{-1}$ exhibit that TS-1 only has relatively weak Lewis acid site, associated with the tetrahedral $\mathrm{Ti}^{4+}$ species in the MFI framework. Regarding to Ti-SBA-15 catalysts, the $1450 \mathrm{~cm}^{-1}$ band of Lewis acid sites grows to an appreciable intensity while the Ti loadings are 2.46-3.76 mol\%, and then gradually decreases in increasing the Ti loadings. Whereas the weak $1540 \mathrm{~cm}^{-1}$ band of Bronsted acid sites is not changed by the $\mathrm{Ti}$ loadings. As to siliceous SBA-15, neither Lewis nor Bronsted acid site is seen. The results suggest again that the $\mathrm{Ti}^{4+}$ species in the tetrahedral coordination sphere are contributed to the Lewis acid sites of Ti-SBA-15 catalysts. A little amount of Bronsted acid site should have to do with the hydroxyl groups on the extra-framework Ti clusters or nanocrystallites [53]. On the other hand, the pure $\mathrm{TiO}_{2}$ catalysts of $\mathrm{TiO}_{2}-\mathrm{S}$ and $\mathrm{TiO}_{2}-\mathrm{L}$ only have a weak band centered at $1450 \mathrm{~cm}^{-1}$, corresponding to Lewis acid site, which is probably related to the surface $\mathrm{Ti}^{4+}$ defect sites [54].

\subsection{Synthesis of BDF over various Ti-SBA-15 and reference catalysts}

The activities of Ti-SBA-15 and reference catalysts in transesterification of CJO with methanol into Jatropha BDF were carried out by a batch-type stainless steel reactor at $200{ }^{\circ} \mathrm{C}$ under autogeneous pressure. Note that CJO contains $8.8 \mathrm{wt} \%$ of FFA, 
corresponding to an acid value of $17.8 \mathrm{mg} \mathrm{KOH} \mathrm{g}^{-1}$, in addition to the main component of TG. The targeting product is FAME, the main component of BDF. The unwanted byproducts are generally TG, DG, MG, G and FFA. The other impurities are sterol derivatives, N-containing compounds and unknowns. Fig. 7 illustrates the transesterification of $\mathrm{CJO}$ with methanol as a function of reaction period over 3Ti-SBA- 15 catalyst at $200{ }^{\circ} \mathrm{C}$ in $\mathrm{N}_{2}$, where the methanol-to-CJO molar ratio is 27 and the catalyst amount is $15 \mathrm{wt} \%$ of CJO. The FAME content quick increases to 61 mass $\%$ in the first hour, reaches 90 mass $\%$ at $3 \mathrm{~h}$ and then stays at $91-93$ mass $\%$ thereafter while the TG content gives an reversed trend. Regarding to the parallel byproducts, the DG and MG contents go to appreciable concentrations at 1-2 h, and then decrease to 1.6 and 3.5 mass $\%$ in $3-5 \mathrm{~h}$, respectively. The FFA content decreases from 4.2 to 2.1 mass $\%$ in the first an hour and then gradually diminishes to 1 mass $\%$ in $1-5$ h. The G and other impurities are kept at low concentrations $(<1$ mass\%). For the purpose of comparing the activities of Ti-SBA-15 and reference catalysts, the results of the Jatropha BDF synthesis after $3 \mathrm{~h}$ are compared hereafter.

The catalytic performances of various catalysts in Jatropha BDF synthesis are tabulated in Table 1. All the Ti-containing catalysts have ability to increase FAME contents with diminishing of TG and unwanted byproducts (Table S3, ESI). The FAME 
contents over TS-1 and Ti-SBA-15 catalysts are around 59-90 mass $\%$, much higher than those of pure $\mathrm{TiO}_{2}$ catalysts. This result indicates that $\mathrm{Ti}$ incorporated in mesoporous SBA-15 and microporous MFI frameworks are superior to that on the surfaces of $\mathrm{TiO}_{2}$ nanocrystallites in catalyzing Jatropha BDF synthesis. Because the molecular diffusion through large mesopores is facilitated, the Ti-SBA-15 catalysts give higher FAME contents than TS-1. Among the Ti-SBA-15 catalysts, a maximum FAME content of 90 mass $\%$ is obtained over 3Ti-SBA-15 catalyst with a Ti loading of $2.46 \mathrm{~mol} \%$. The siliceous SBA-15 and H-ZSM-5 catalysts only give $22-24$ mass $\%$ of FAME contents accompanying with large amounts of nonreactive TG and unwanted byproducts. The results resemble the blank test. Evidently, neither mesoporous SBA-15 nor microporous MFI framework is active in Jatropha BDF synthesis. Note that the FFA content over H-ZSM-15 prompt increases to 25 mass \%. The strong acidic H-ZSM-5 catalyst seems favorable for the dehydration of methanol into dimethyl ester and water. The unwanted FFA and other byproducts are then formed by hydrolysis of TG with water.

$\mathrm{R}_{\mathrm{TG}}$ was determined at the first 30-60 min of the reaction, where the conversions of TG were lower than 40 mass $\%$. The $\mathrm{R}_{\mathrm{TG}}$ values of Ti-SBA-15 catalysts are around 5.1-6.2 mmol g-cat ${ }^{-1} \mathrm{~h}^{-1}$, higher than those of SBA-15, H-ZSM-5, TS-1 and three $\mathrm{TiO}_{2}$ catalysts. Again, the 3Ti-SBA-15 catalyst gives a highest $\mathrm{R}_{\mathrm{TG}}$ value. Fig. 8 correlates 
the FAME content with the amounts of strongly, moderately and weakly acidic sites in various Ti-containing catalysts (Table S2, ESI). The FAME content increases positively in increasing the amount of weakly acidic site. Moreover, the variation of the FAME content as a function of weakly acidic site is almost in the same trend as the changes in the amount of tetrahedral $\mathrm{Ti}^{4+}$ species in TS-1 and Ti-SBA-15 catalysts estimated by DR UV-Vis and DRIFT spectra (Fig. 4(B), and Fig. S1 and S2, ESI). It should be noticed that the strongly and moderately acidic sites, probably originated from the coordinatively unsaturated $\mathrm{Ti}^{4+}$ species as surface defect sites of anatase $\mathrm{TiO}_{2}$ nanocrystallites, may also catalyze Jatropha BDF synthesis, especially for $\mathrm{TiO}_{2}-\mathrm{M}$ and $\mathrm{TiO}_{2}-\mathrm{S}$ catalysts. The relatively low FAME contents over $\mathrm{TiO}_{2}-\mathrm{M}$ and $\mathrm{TiO}_{2}-\mathrm{S}$ catalysts can be explained by a few numbers of strongly and moderately acidic sites on surfaces. On the other hand, the weakly acidic sites of H-ZSM-5 and siliceous SBA-15, derived from surface silanol group, have nothing to do with Jatropha BDF synthesis. The strongly and moderately acidic sites of H-ZSM-5 have negative influence on formation of unwanted FFA byproduct. By combination of catalytic study with various characterizations, it allows us to conclude that the catalytically active sites related to the production of Jatropha BDF over Ti-SBA-15 catalysts are the tetrahedral $\mathrm{Ti}^{4+}$ species with mostly weak Lewis acid character. To get high FAME content with reasonable $\mathrm{R}_{\mathrm{TG}}$ 
value, the 3 Ti-SBA-15 catalyst is qualified as the best catalyst hereafter.

\subsection{Synthesis of high-quality BDF}

The quality of BDF is strictly required to meet with the international fuel standards in order to avoid any damages of vehicle's engine and exhaust system. According to the specified requirements by European standard (EN 14214:2009), the marketed and delivered BDF products to be used as fuel for diesel engine should have a FAME content of min. 96.5 mass $\%$, and the $\mathrm{G}_{\mathrm{T}}$, TG, DG, MG and G contents of max. 0.25, $0.20,0.20,0.80$, and 0.02 mass $\%$, respectively. To drive the transesterification of CJO with methanol into Jatropha BDF completely, more methanol was used. Fig. 9 shows the effect of methanol-to-oil molar ratio on the reaction pressure and the composition of Jatropha BDF over $3 \mathrm{Ti}-\mathrm{SBA}-15$ catalyst at $200{ }^{\circ} \mathrm{C}$ for $3 \mathrm{~h}$, where the catalyst amount is kept at $15 \mathrm{wt} \%$ of CJO. The autogeneous reaction pressure of gasified methanol increases promptly from 9 to 32 bar as the methanol-to-oil molar ratio increases from 14 to 108 and then stays at 32-34 bar when more methanol is used. Regarding to the FAME content, it rapid increases from 62.4 to 92.8 mass $\%$ as the methanol-to-oil molar ratio increases from 14 to 41 , grows to $95.7-96.1$ mass $\%$ for the methanol-to-oil molar ratios 
of 54-81, and stays around $97.8-98.6$ mass \% thereafter. Regarding to the MG, DG, TG and $\mathrm{G}$ contents, an opposite trend is seen. As the methanol-to-oil molar ratio is equal to or higher than 108, where the gasified methanol is a sub-supercritical fluid [34], the $\mathrm{G}_{\mathrm{T}}$ values calculated by equation (1) are around $0.063-0.16$ mass $\%$, which is within the European standard limitation. On the other hand, the quality of BDF synthesized by TS-1 catalyst also fills the European standard if the methanol-to-oil molar ratio is 108 whereas those synthesized by $\mathrm{TiO}_{2}-\mathrm{S}$ and $\mathrm{Fe}$-impregnated silica catalysts are unqualified (Table S4, ESI) [49]. This result suggests that the sub-supercritical methanol fluid is particularly useful for carrying the reactants to the catalytically active sites close to the pore mouths of microporous TS-1 catalyst for transesterification and expelling of the products from the catalytically active sites after transesterification. The ICP-OES technique was further utilized to examine the leaching of Ti species from Ti-containing catalysts based on the procedures of prEN 14538 method. The results show that the Jatropha BDF products synthesized by TS-1 and 3Ti-SBA-15 catalysts have no eluted $\mathrm{Ti}$ species whereas that by $\mathrm{TiO}_{2}-\mathrm{S}$ catalyst contains around $1.8 \mathrm{ppm}$ of eluted Ti species. It is therefore confirmed that both TS-1 and 3Ti-SBA-15 catalysts are efficient and stable Lewis solid acids for the production of high-quality Jatropha BDF using a methanol-to-oil ratio of 108 at moderate condition. 


\subsection{Water and FFA tolerance levels}

Since the amounts of water, lauric acid (LA) and lauric acid triglycerides in CJO are negligible, the water and FFA tolerance levels of 3Ti-SBA-15 catalysts are studied by adding varied amounts of water or LA to the reaction medium. Table 2 shows the influences of water and FFA amounts on activities of $3 \mathrm{Ti}-\mathrm{SBA}-15, \mathrm{TS}-1$ and $\mathrm{TiO}_{2}-\mathrm{S}$ catalysts in high-quality Jatropha BDF synthesis at $200{ }^{\circ} \mathrm{C}$ for $3 \mathrm{~h}$. The methanol-to-oil molar ratio is 108 , corresponding to an autogeneous pressure of 32 bar. With adding 30 $\mathrm{wt} \%$ of LA to the reaction medium, the 3Ti-SBA-15 catalyst gives 98.9 mass $\%$ of lauric acid methyl ester (LAME) through the esterification of LA with methanol and the quality of Jatropha BDF can meet with the European standard. Above this LA amount, the resulting Jatropha BDF products have unqualified MG contents of $0.84-0.85$ mass $\%$

(Table S5, ESI). By contrast, the Jatropha BDF products synthesized by TS-1 and $\mathrm{TiO}_{2}-\mathrm{S}$ catalysts have lower FAME contents of $76.8-95.0$ mass $\%$ and higher $\mathrm{G}_{\mathrm{T}}$ values of 0.74-3.7 mass, which are unqualified for the European standard, although they are able to carry out esterification of LA with methanol.

The quality of Jatropha BDF synthesized by Ti-containing catalysts is significantly 
influenced by water added to the reaction medium. The Jatropha BDF synthesized by 3Ti-SBA-15 catalyst can meet with the European standard only if the amount of water added to reaction medium is equal to or lower than $2 \mathrm{wt} \%$ at $200{ }^{\circ} \mathrm{C}$ for $3 \mathrm{~h}$. Above this ratio, the resulting Jatropha BDFs are unqualified for the European standard (Table 2 and Table S6, ESI). When the reaction period is doubled, the high-quality Jatropha BDF can be synthesized by 3Ti-SBA-15 catalyst even though $5 \mathrm{wt} \%$ of water is added to the reaction mixture. The high water tolerance level of Ti-SBA-15 catalysts is probably due to the well-ordered mesostructure with largely hydrophilic surfaces as a good medium for water adsorption based on the DRIFT study (Fig. S2, ESI) [17,38]. By contrast, the TS-1 and $\mathrm{TiO}_{2}-\mathrm{S}$ catalysts with low and hydrophobic surfaces are seriously poisoned by water and only give very low-quality BDF products under the same condition.

\subsection{Possible reaction mechansim}

The proposed reaction mechanism of high-quality BDF synthesis over Ti-SBA-15 catalysts is illustrated in Scheme 1. TG is simplified by the starting ester of $\mathrm{R}_{2} \mathrm{COOR}_{1}$, where $R_{1}$ and $R_{2}$ represent the glycerol part and the long carbon chain of fatty acid part, respectively. On the surface of Ti-SBA-15 catalysts, the carbonyl group of the staring 
ester is coordinated on the tetrahedral $\mathrm{Ti}^{4+}$ species as the proposed active site (I) through oxygen atom to form a Lewis complex, i.e. intermediate (II) [2]. Meanwhile, methanol is probably activated by stabilizing the $\mathrm{H}$ atom on hydroxyl group through hydrogen bonding with lattice oxygens from the surrounding tetrahedral $\mathrm{Ti}^{4+}$ species [45]. The carbonyl group of Lewis complex then undergoes nucleophilic attack by the activated methanol to give a tetrahedral intermediate (III). As the electron on $\mathrm{C}-\mathrm{O}$ back donates to carbon and the $\mathrm{O}-\mathrm{R}_{1}$ group attacks the $\mathrm{H}$ atom on vicinal hydroxyl group, the intermediate (IV) with new ester and alcohol of $\mathrm{R}_{2} \mathrm{COOCH}_{3}$ and $\mathrm{R}_{1} \mathrm{OH}$ are formed, where $\mathrm{R}_{2} \mathrm{COOCH}_{3}$ is FAME, i.e. BDF, and $\mathrm{R}_{1} \mathrm{OH}$ is DG, MG or G. In the final step, an excess amount of methanol plays as a solvent to take the new ester and alcohol away from the tetrahedral $\mathrm{Ti}^{4+}$ species, and then the catalytically active sites (I) are regenerated for the next catalytic cycle. It has shown that the catalytic cycle can be greatly facilitated in a sub-supercritical methanol fluid, especially for microporous TS-1 catalyst.

The esterification of FFA with methanol can be also catalyzed by the tetrahedral $\mathrm{Ti}^{4+}$ species in Ti-SBA-15 catalyst through the proposed reaction mechanism where $\mathrm{R}_{1}$ is replaced with the $\mathrm{H}$ atom. Since esterification proceeds faster than transesterification, water formed as a byproduct from esterification may occupy the tetrahedral $\mathrm{Ti}^{4+}$ species 
and hinder the regeneration of catalytically active sites for the next cycle. Fortunately, the amount of water produced from esterification is around $2.7 \mathrm{wt} \%$ when $30 \mathrm{wt} \%$ of LA is added to the reaction medium and it is still lower than the water tolerance level of 3Ti-SBA-15 catalyst. Therefore, the esterification and transesterification can be simultaneously catalyzed by 3 Ti-SBA-15 catalyst under optimal condition and the resulting Jatropha BDF can meet with international fuel standard.

\subsection{Regeneration}

The used 3Ti-SBA-15 catalyst separated from the BDF product was washed with acetone, dried and regenerated by calcining at $500{ }^{\circ} \mathrm{C}$ for $3 \mathrm{~h}$ in air. Table 3 shows the structural property, acid capacity and catalytic activity of regenerated 3Ti-SBA-15 catalyst (shortly termed Reg-3Ti-SBA-15) in comparison to that of fresh 3Ti-SBA-15 catalyst. For the first and second regenerations, the activity of Reg-3Ti-SBA-15 catalyst in high-quality BDF synthesis is maintained although the $\mathrm{S}_{\mathrm{BET}}, \mathrm{V}_{\text {Total }}$ and acid capacity slightly decrease to $469-528 \mathrm{~m}^{2} / \mathrm{g}, 0.72 \mathrm{~cm}^{3} / \mathrm{g}, 7.3-7.4 \mathrm{~nm}$ and $1.29-1.53 \mathrm{mmol}$ g-catal ${ }^{-1}$, respectively. The surface area and acid capacity of Reg-3Ti-SBA-15 catalyst are further

decreased to $414 \mathrm{~m}^{2} / \mathrm{g}$ and $1.03 \mathrm{mmol}$ g-catal ${ }^{-1}$, respectively, after the third regeneration. 
The quality of Jatropha BDF is slightly lower than the European standard due to the unqualified MG content. Albe-Rubio et al. reported that the sulfonic acid-functionalized SBA-15 catalyst was significantly deactivated after the first regeneration due to the leaching of the sulfonic groups and the formation of organic deposits during the BDF synthesis [19]. The ICP-OES study has confirmed that no active Ti species are leached from the 3Ti-SBA-15 catalysts. A little change of the 3Ti-SBA-15 catalyst after each reuse can be explained by loss of surface area due to further silica condensation upon the calcination treatment, especially for microporosity. The $\mathrm{N}_{2}$ physisorption data indicate that the microporous surface area is around $250 \mathrm{~m}^{2} \mathrm{~g}^{-1}$ for the fresh 3Ti-SBA-15 catalyst and promptly dropped to $54-106 \mathrm{~m}^{2} \mathrm{~g}^{-1}$ for the Reg-3Ti-SBA-15 catalysts (Fig. S3, ESI). After the regeneration for several times, the catalytically active sites of tetrahedral $\mathrm{Ti}^{4+}$ species close to the micropores are probably covered by the condensed silica frameworks and not fully accessible to the reactant molecules. This is also explained that the acidity of Reg-3Ti-SBA-15 catalyst is gradually decreased by the number of regeneration times.

\subsection{High-quality BDFs derived from various vegetable oils}


The transesterification of various edible and non-edible vegetable oils with different acid values of $1.47-190 \mathrm{mg} \mathrm{KOH} \mathrm{g}^{-1}$ over 3 Ti-SBA-15 catalyst was also examined at $200{ }^{\circ} \mathrm{C}$ using a methanol/oil molar ratio of 108 and a catalyst amount of 15 $w t \%$. Table 4 shows that all the BDF products derived from various vegetables are qualified for the European standard, except that made by PFAD with a highest acid value of $190 \mathrm{mg} \mathrm{KOH} \mathrm{g}^{-1}$. By increasing the catalyst amount and the reaction period to $30 \mathrm{wt} \%$ of PFAD and $5 \mathrm{~h}$, respectively, the resulting PFAD BDF can meet with European standard. In other words, the 3Ti-SBA-15 catalyst has ability to one-step transform a great diversity of vegetable oils with various acid values into high-quality BDFs at $200{ }^{\circ} \mathrm{C}$ under autogeneous pressure without any pretreatments or complicated processing steps.

\section{Conclusions}

Well-ordered Ti-SBA-15 mesoporous materials with Ti loadings up to $6.78 \mathrm{~mol} \%$ were used as solid acid catalysts for the production of high-quality BDFs at $200{ }^{\circ} \mathrm{C}$ under autogeneous pressure. Ti was incorporated in mesoporous silica frameworks as tetrahedral and octahedral species when the Ti loadings were equal to or lower than 5.83 
mol\%. Above this ratio, it aggregated to form small $\mathrm{TiO}_{2}$ nanocrystallites. The acid density of studied catalysts measured by pulsed $\mathrm{NH}_{3}$ chemisorption decreased in the following matter: H-ZSM-5 $>$ 1-10Ti-SBA-15 $>$ SBA-15 $>$ TS-1 $>\mathrm{TiO}_{2}-\mathrm{S}>\mathrm{TiO}_{2}-\mathrm{M}>$ $\mathrm{TiO}_{2}$-L. The Ti-SBA-15 catalysts showed mostly weak Lewis acid character with a differential heat of $\mathrm{NH}_{3}$ adsorption smaller than $90 \mathrm{~kJ} \mathrm{mmol}^{-1}$, which was derived from the superficially tetrahedral $\mathrm{Ti}^{4+}$ species. For the transesterification of non-edible CJO with methanol, the catalytic activity decreased in the order of 1-10Ti-SBA-15 $>$ TS-1 > $\mathrm{TiO}_{2}-\mathrm{S}>\mathrm{TiO}_{2}-\mathrm{M}>\mathrm{TiO}_{2}-\mathrm{L}>\mathrm{H}-\mathrm{ZSM}-5 \sim \mathrm{SBA}-15 \sim$ blank test. All the Ti-containing catalysts are active in Jatropha BDF synthesis whereas the siliceous SBA-15 has almost no activity and the strongly acidic H-ZSM-5 zeolite gave negatively affect on production of unwanted FFA byproduct. The Ti-SBA-15 catalysts exhibited much higher activity than zeolitic TS-1 and pure $\mathrm{TiO}_{2}$ catalysts. The catalytically active sites are mainly associated to the tetrahedral $\mathrm{Ti}^{4+}$ species with weak Lewis acid character. Among them, a 90 mass $\%$ of FAME content with a $\mathrm{R}_{\mathrm{TG}}$ value of $6.2 \mathrm{mmol} \mathrm{g-cat}^{-1} \mathrm{~h}^{-1}$ was obtained over 3Ti-SBA-15 catalyst with a Ti loading of $2.46 \mathrm{~mol} \%$ at $200{ }^{\circ} \mathrm{C}$ using a methanol-to-oil molar ratio of 27 . The low activity of TS-1 catalyst was attributed to the mass transfer limitation of bulky oil molecules through the micropores. The pure $\mathrm{TiO}_{2}$ catalysts showed moderate activities in BDF synthesis due to a few numbers of 
strongly and moderately acidic sites derived from the surface defect sites of tetrahedral $\mathrm{Ti}^{4+}$ species. When the methanol-to-oil molar ratios were equal to or higher than 108 , high-quality Jatropha BDFs derived from a great variety of edible and non-edible vegetable oils were synthesized over 3 Ti-SBA-15 catalyst at $200{ }^{\circ} \mathrm{C}$ for $3-6 \mathrm{~h}$. The 3Ti-SBA-15 catalyst could be regenerated by calcination treatment although the acidic capacity and catalytic activity are slightly decreased after the third regeneration. Most importantly, the 3Ti-SBA-15 catalyst showed excellent water and FFA tolerance levels, which were several ten times better than those of TS- 1 and $\mathrm{TiO}_{2}-\mathrm{S}$ reference catalysts as well as the homogeneous and heterogeneous catalysts in the current BDF production technology.

\section{Acknowledgements}

This research was supported by JST-JICA's SATREPS project. Acknowledgements are extended to Dr. A. Endo and Dr. A. Kawai of Research Institute for Innovation in Sustainable Chemistry, AIST, for XRD experiment, Dr. Y. Miseki and Dr. K. Sayama of Energy Technology Research Institute, AIST, for UV-Vis experiment, and Mr. M. Kaitsuka and Dr. M. Oguma of Research Center for New Fuels and Vehicle Technology, 
AIST, for ICP-OES analysis.

\section{References:}

1. S. Chu, A Majumdar, Nature 448 (2012) 294.

2. M. D. Serio, R. Tesser, L. Pengmei, E. Santacesaria, Energy and Fuel 22 (2008) 207.

3. J. A. Melero, J. Iglesias, G. Morales, Green Chemistry 11 (2009), 1285.

4. R. Rinaldi, F. Schuth, Energy and Environmental Science 2 (2009) 610.

5. K. Wilson, A.F. Lee, Catalysis Science and Technology 2 (2012) 884.

6. R. Stern, G. Hillion, J. J. Rouxel, S. Leporq, United States Patent 5,908,946 (1999).

7. L. Bournay, D. Casanve, B. Delfort, G. Hillion, J.A. Chodorge, Catalysis Today 106 (2005) 190.

8. N. Gilbert, Nature News, doi:10.1038/nature.2012.11145.

9. R. Snowdon, W. Friedt, Nature 490 (2013) 37.

10. R. S. Service, Science 326 (2009) 516.

11. I. K. Mbaraka, D. R. Radu, V. S. Y. Lin, B. H. Shanks, Journal of Catalysis 219 (2003) 329.

12. I. K. Mbaraka, B. H. Shanks, Journal of Catalysis 229 (2005) 365.

13. I. K. Mbaraka, B. H. Shanks, Journal of Catalysis 244 (2006) 78. 
14. D. E. Lopez, K. Suwannakarn, D. A. Bruce, J. G. Goodwin Jr., Journal of Catalysis $247(2007) 43$.

15. K. Suwannakarn, E. Lotero, J. G. Goodwin Jr., GC. Lu, Journal of Catalysis 255 (2008) 279.

16. H. J. Berchmans, S. Hirata, Bioresource Technology 99 (2008) 1716.

17. S. Y. Chen, T. Yokoi, C. Y. Tang, L. Y. Jang, T. Tatsumi, J. C. C. Chan, S. Cheng, Green Chemistry 13 (2011) 2920.

18. A. Macario, G. Giordano, Catalysis Letter 143 (2013) 159.

19. A.C. Alba-Rubio, F. Vila, D. M. Alonso, M. Ojeda, R. Mariscal, M. L. Granados, Applied Catalysis B: Environmental 95 (2010) 279.

20. V. Brahmkhatri, A. Patel, Applied Catalysis A: General 403 (2011) 161.

21. R. Sheikh, M. S. Choi, J. S. Im, Y. H. Park, Journal of Industrial and Engineering Chemistry 19 (2013) 1413.

22. M. Taramasso, G. Perego, B. Notari, United States Patent 4,410,501, (1983).

23. A. Thangraj, R. Kumar, S. P. Mirajkar, P. Ratnasamy, Journal of Catalysis 130 (1991) 1 .

24. A. Thangaraj, R. Kumar, P. Ratnasamy, Journal of Catalysis 131 (1991) 294.

25. P. Wu, T. Tatsumi, T. Komatsu, T. Yashima, Journal of Catalysis 202 (2001) 245. 
26. F. Song, Y. Liu, H. Wu, M. He, P. Wu, T. Tatsumi, Journal of Catalysis 237 (2006) 359.

27. W. Fan, R. G. Duan, T. Yokoi, P. Wu, Y. Kubata, T. Tatsumi, Journal of American Chemical Society 130 (2008) 10150.

28. W. H. Zhang, J. Lu, B. Han, M. Li, J. Xiu, P. Ying, C. Li, Chemistry of Materials 14 (2002) 3413.

29. Y. Chen, Y. Huang, J. Xiu, X. Han and X. Bao, Applied Catalysis A:General 273 (2004) 185 .

30. K. Lin, P. P. Pescarmona, H. Vandepitte, D. Liang, G. V. Tendeloo, P. A. Jacobs, Journal of Catalysis 254 (2008) 64.

31. S. Y. Chen, C. Y. Tang, J. F. Lee, L. Y. Jang, T. Tatsumi, S. Cheng, Journal of Materials Chemistry 21 (2011) 2255.

32. D. Shrinvas, R. Srivastava and P. Ratnasamy, Catalysis Today 96 (2004) 127.

33. T. Oku, M. Nonoguchi, T. Moriguchi, PCT. Patent 2005/021697 A1 (2005).

34. T. Oku, M. Nonoguchi, T. Moriguchi, H. Izumi, A. Tachibana, T. Akatsuka, RSC Advanced 2 (2012) 8619.

35. D. Siano, L. Siano, M. Nastashi, E. Santacesria, M. Di Serio, PCT. Patent 2006/094986 A1 (2006). 
36. M. Cozzolino, R. Tesser, M. Di Serio, M. Ledda, G. Minutillo, E. Santacesaria, Studied in Surface Science and Catalysis 162 (2006) 299.

37. M. Di Serio, R. Tesser, L. Casale, A. D. Angelo, M. Trifuoggi, E. Santacesaria, Topics in Catalysis 53 (2010) 811.

38. S. Y. Chen, T. Mochizuki, Y. Abe, M. Toba, Y. Yoshimura, Catalysis Communications 41 (2013) 136.

39. D. Zhao, J. Feng, Q. Huo, N. Melosh, G. H. Fredrickson, B. F. Chmelka, G. D. Stucky, Science 279 (1998) 548.

40. W. W. Lukens, P. Schmidt-Winkel, D. Zhao, J. Feng, G. D. Stucky, Langmuir 15 (1999) 5403.

41. S. Y. Chen, Y. T. Chen, J. J. Lee and S. Cheng, Journal of Materials Chemistry 21 (2011) 5693.

42. C. Paquot, Pure and Applied Chemistry 54 (1982) 233.

43. M. S. Wong, H. C. Huang, J. Y. Ying, Chemistry of Materials 14 (2002) 1961.

44. S.Y. Chen, H. D. Tsai, W. T. Chuang, J. J. Lee, C. Y. Tang, C. Y. Lin, S. Cheng, Journal of Physical Chemistry C 113 (2009) 15226.

45. S. Y. Chen, J. F. Lee, S. Cheng, Journal of Catalysis 270 (2010) 196.

46. S. Y. Chen, C. Y. Tang, W. T. Chuang, J. J. Lee, Y. L. Tsai, J. C. C. Chan, C. Y. 
Lin, Y. C. Liu, S. Cheng, Chemistry of Materials 20 (2008) 3906.

47. P. Yang, D. Zhao, D. I. Margolese, B. F. Chmelka, G. D. Stucky, Nature 396 (1998) 152.

48. F. T. Kuo, S. Y. Chen, T. H. Lin, J. F. Lee, S. Cheng, RSC Advances 3 (2013) 12604.

49. T. Suzuta, M. Toba, Y. Abe, Y. Yoshimura, Journal of American Oil Chemical Society 89 (2012) 1981.

50. T. Mochizuki, S. Y. Chen, M. Toba, Y. Yoshimura, Applied Catalysis B: Environmental 146 (2014) 237.

51. E. P. Parry, Journal of Catalysis 2 (1963) 371.

52. N. Y. Topsoe, F. Joensen, E. G. Derouane, Journal of Catalysis 110 (1998) 404.

53. M. Kitano, E. Wada, K. Nakajima, S. Hayashi, S. Miyazaki, H. Kobayashi, M. Hara, Chemistry of Materials 25 (2013) 385.

54. I. X. Green, C. Buda, Z. Zhang, M. Neurock, J. T. Yates, Journal of Physical Chemistry C 114 (2010) 16649. 
Table 1. The textural and catalytic properties of the $500{ }^{\circ} \mathrm{C}$ calcined Ti-SBA- 15 and reference materials. ${ }^{\mathrm{a}}$

\begin{tabular}{|c|c|c|c|c|c|c|c|c|c|}
\hline Catalysts & $\begin{array}{l}\mathrm{Ti} / \mathrm{Si} \\
(\mathrm{mol} \%)\end{array}$ & $\begin{array}{l}\mathrm{TiO}_{2} \operatorname{size}^{\mathrm{b}} \\
(\mathrm{nm})\end{array}$ & $\begin{array}{l}\mathrm{S}_{\mathrm{BET}} \\
\left(\mathrm{m}^{2} / \mathrm{g}\right)\end{array}$ & $\begin{array}{l}V_{p} \\
\left(\mathrm{~cm}^{3} / \mathrm{g}\right)\end{array}$ & $\begin{array}{l}\Phi \\
(\mathbf{n m})\end{array}$ & $\begin{array}{l}\text { Acid Capacity } \\
\left(\mathrm{mmol}^{\left.- \text {-cat }^{-1}\right)}\right.\end{array}$ & $\begin{array}{l}R_{\mathrm{TG}} \\
\left(\mathrm{mmol} \mathrm{g-cat}{ }^{-1} h^{-1}\right)\end{array}$ & $\begin{array}{l}\text { FAME }^{\mathrm{c}} \\
(\operatorname{mass} \%)\end{array}$ & $\begin{array}{l}\text { FFA }^{\mathrm{c}} \\
(\operatorname{mass} \%)\end{array}$ \\
\hline None & - & - & - & - & & - & - & 23 & 8.9 \\
\hline SBA-15 & - & - & 914 & 1.1 & 7.5 & 1.65 & 1.5 & 24 & 5.7 \\
\hline H-ZSM-5 & $8.6^{\mathrm{d}}$ & - & 343 & 0.23 & 0.56 & 2.83 & 1.8 & 22 & 25 \\
\hline $\mathrm{TiO}_{2}-\mathrm{L}$ & - & 84.7 & 11 & 0.10 & 8.7 & 0.13 & 1.6 & 34 & 4.4 \\
\hline $\mathrm{TiO}_{2}-\mathrm{M}$ & - & 25.5 & 128 & 0.32 & 9.2 & 0.59 & 1.7 & 40 & 4.6 \\
\hline $\mathrm{TiO}_{2}-\mathrm{S}$ & - & 15.0 & 164 & 0.38 & 7.9 & 0.71 & 2.0 & 55 & 3.5 \\
\hline TS-1 & 2.86 & n.d. & 405 & 0.27 & 0.56 & 1.21 & 2.0 & 59 & 0.85 \\
\hline 1Ti-SBA-15 & 0.808 & n.d. & 811 & 0.96 & 7.9 & 1.84 & 5.1 & 82 & 1.5 \\
\hline 3Ti-SBA-15 & 2.46 & n.d. & 746 & 0.83 & 7.6 & 2.05 & 6.2 & 90 & 1.2 \\
\hline 5Ti-SBA-15 & 3.76 & n.d. & 717 & 0.86 & 7.1 & 2.09 & 6.0 & 88 & 1.7 \\
\hline 7Ti-SBA-15 & 5.83 & n.d. & 703 & 0.80 & 7.3 & 2.09 & 5.4 & 86 & 1.7 \\
\hline 10Ti-SBA-15 & 6.78 & 6.3 & 677 & 0.80 & 7.3 & 1.78 & 5.4 & 75 & 4.2 \\
\hline $\begin{array}{cc}\mathrm{a} & \text { Reaction cor } \\
& \text { catalyst (1 } \\
\mathrm{b} & \text { Determined } \\
\mathrm{c} & \text { Analyzed by } \\
\mathrm{d} & \text { The Al/Si m }\end{array}$ & $\begin{array}{l}200{ }^{\circ} \mathrm{C} \text { for } \\
\text { oil). } \\
\text { rer equatic } \\
03: 2009 \mathrm{~m} \\
\end{array}$ & $\begin{array}{l}3 \text { h under au } \\
\text { on. The "n.d. } \\
\text { nethod. }\end{array}$ & $\begin{array}{l}\text { genous } \\
\text { represe }\end{array}$ & ats "not d & etectab & $\begin{array}{l}\text { bar), } 2.5 \mathrm{~g} \\
\text { le". }\end{array}$ & $\mathrm{nmol}), 2.5 \mathrm{~g} \mathrm{M}$ & $78.1 \mathrm{~m}$ & $0.375 \mathrm{~g}$ \\
\hline
\end{tabular}


Table 2. Effects of water and FFA amounts on quality of Jatropha BDF over 3 Ti-SBA-15, TS-1 and $\mathrm{TiO}_{2}$-S catalysts. ${ }^{\mathrm{a}}$

\begin{tabular}{|c|c|c|c|c|c|c|c|c|c|}
\hline Catalysts & $\begin{array}{l}\text { LA/CJO } \\
(w t \%)\end{array}$ & $\begin{array}{l}\mathrm{H}_{2} \mathrm{O} / \mathrm{CJO} \\
(\mathrm{wt} \%)\end{array}$ & $\begin{array}{l}\text { LAME } \\
(\operatorname{mass} \%)\end{array}$ & $\begin{array}{l}\text { FAME } \\
(\operatorname{mass} \%)\end{array}$ & $\begin{array}{l}G_{T} \\
(\operatorname{mass} \%)\end{array}$ & $\begin{array}{l}\text { TG } \\
(\operatorname{mass} \%)\end{array}$ & $\begin{array}{l}\text { DG } \\
(\operatorname{mass} \%)\end{array}$ & $\begin{array}{l}\text { MG } \\
(\operatorname{mass} \%)\end{array}$ & $\begin{array}{l}G \\
(\operatorname{mass} \%)\end{array}$ \\
\hline 3Ti-SBA-15 & 30 & - & 98.9 & 97.9 & 0.21 & 0.069 & 0.082 & 0.68 & 0.020 \\
\hline TS-1 & 30 & - & 99.2 & 95.0 & 0.74 & 1.2 & 0.48 & 2.0 & 0.035 \\
\hline $\mathrm{TiO}_{2}-\mathrm{S}$ & 30 & - & 93.5 & 76.8 & 3.7 & 7.1 & 7.5 & 6.6 & 0.18 \\
\hline \multirow[t]{3}{*}{ 3Ti-SBA-15 } & - & 2 & - & 98.0 & 0.22 & 0.04 & 0.07 & 0.71 & 0.020 \\
\hline & & 5 & - & 94.8 & 0.83 & 0.18 & 0.76 & 2.5 & 0.061 \\
\hline & & $5^{\mathrm{b}}$ & & 98.0 & 0.20 & 0.026 & 0.066 & 0.69 & 0.0070 \\
\hline TS-1 & - & $5^{\mathrm{b}}$ & - & 79.4 & 3.7 & 4.8 & 5.5 & 8.9 & 0.18 \\
\hline $\mathrm{TiO}_{2}-\mathrm{S}$ & - & $5^{\mathrm{b}}$ & - & 51.2 & 7.2 & 20.3 & 17.5 & 8.8 & 0.32 \\
\hline EN 14214:2009 standard & - & - & & $>96.5$ & $<0.25$ & $<0.20$ & $<0.20$ & $<0.80$ & $<0.02$ \\
\hline
\end{tabular}

a Reaction condition: $200{ }^{\circ} \mathrm{C}$ for $3 \mathrm{~h}$ under autogenous pressure (ca. $\left.32 \mathrm{bar}\right), 2.5 \mathrm{~g} \mathrm{CJO}$ (2.89 mmol), $10 \mathrm{~g} \mathrm{MeOH} \mathrm{(313} \mathrm{mmol),} 0.375 \mathrm{~g}$ catalyst ( $15 \mathrm{wt} \%$ of oil).

b The reaction period is lengthened to $6 \mathrm{~h}$. 
Table 3. Structural property, acid capacity and activity of fresh and regenerated 3Ti-SBA-15 catalysts. ${ }^{a}$

\begin{tabular}{|c|c|c|c|c|c|c|c|c|c|c|c|}
\hline Catalyst & No. of Regeneration & $\begin{array}{l}\mathrm{S}_{\text {BET }} \\
\left(\mathrm{m}^{2} / \mathbf{g}\right)\end{array}$ & $\begin{array}{l}V_{p} \\
\left(\mathrm{~cm}^{3} / \mathrm{g}\right)\end{array}$ & $\begin{array}{l}\Phi \\
(\mathbf{n m})\end{array}$ & $\begin{array}{l}\text { Acid Density } \\
\left(\mathrm{mmol} \mathrm{g-cat}^{-1}\right)\end{array}$ & $\begin{array}{l}\text { FAME } \\
(\text { mass\%) }\end{array}$ & $\begin{array}{l}\mathbf{G}_{\mathrm{T}} \\
(\operatorname{mass} \%)\end{array}$ & $\begin{array}{l}\text { TG } \\
\text { (mass\%) }\end{array}$ & $\begin{array}{l}\text { DG } \\
(\operatorname{mass} \%)\end{array}$ & $\begin{array}{l}\text { MG } \\
\text { (mass\%) }\end{array}$ & $\begin{array}{l}\text { G } \\
(\operatorname{mass} \%)\end{array}$ \\
\hline 3Ti-SBA-15 & - & 746 & 0.83 & 7.6 & 2.05 & 98.4 & 0.19 & 0.054 & 0.045 & 0.66 & 0.010 \\
\hline \multirow[t]{3}{*}{ Reg-3Ti-SBA-15 } & 1 & 528 & 0.72 & 7.3 & 1.53 & 98.5 & 0.18 & 0.032 & 0.041 & 0.63 & 0.0070 \\
\hline & 2 & 469 & 0.72 & 7.4 & 1.29 & 98.5 & 0.20 & 0.055 & 0.052 & 0.71 & 0.0061 \\
\hline & 3 & 414 & 0.70 & 7.3 & 1.04 & 98.1 & 0.28 & 0.11 & 0.094 & 0.95 & 0.0083 \\
\hline
\end{tabular}

Reaction condition: $200{ }^{\circ} \mathrm{C}$ for $3 \mathrm{~h}$ under an autogenous pressure (ca. $\left.32 \mathrm{bar}\right), 2.5 \mathrm{~g} \mathrm{CJO}$ (2.89 mmol), $10 \mathrm{~g} \mathrm{MeOH} \mathrm{(313} \mathrm{mmol),} 0.375$ g catalyst. 
Table 4. The BDF products derived from various vegetable oils over 3Ti-SBA-15 catalsyt. ${ }^{\text {a }}$

\begin{tabular}{|c|c|c|c|c|c|c|c|}
\hline Oils & $\begin{array}{l}\text { Acid Value } \\
\left(\mathrm{mg} \mathrm{KOH} \mathrm{g}^{-1}\right)\end{array}$ & $\begin{array}{l}\text { FAME } \\
(\operatorname{mass} \%)\end{array}$ & $\begin{array}{l}\mathrm{G}_{\mathrm{T}} \\
(\operatorname{mass} \%)\end{array}$ & $\begin{array}{l}\text { TG } \\
\text { (mass\%) }\end{array}$ & $\begin{array}{l}\text { DG } \\
\text { (mass\%) }\end{array}$ & $\begin{array}{l}\text { MG } \\
(\operatorname{mass} \%)\end{array}$ & $\begin{array}{l}G \\
(\operatorname{mass} \%)\end{array}$ \\
\hline RSO & 0.06 & 98.0 & 0.21 & 0.059 & 0.14 & 0.65 & 0.018 \\
\hline RRO & 0.12 & 97.8 & 0.18 & 0.045 & 0.064 & 0.60 & 0.016 \\
\hline WCO & 1.47 & 97.6 & 0.15 & 0.062 & 0.10 & 0.49 & 0.0039 \\
\hline $\mathrm{CPO}$ & 13.5 & 98.4 & 0.22 & 0.074 & 0.10 & 0.70 & 0.016 \\
\hline CJO & 17.8 & 98.4 & 0.19 & 0.054 & 0.045 & 0.66 & 0.010 \\
\hline \multirow[t]{2}{*}{ PFAD } & 190 & 95.3 & 0.34 & 0.026 & 0.58 & 0.56 & 0.011 \\
\hline & $190^{\mathrm{b}}$ & 97.4 & 0.083 & 0.057 & 0.14 & 0.17 & 0.011 \\
\hline
\end{tabular}

a Reaction condition: $200{ }^{\circ} \mathrm{C}$ for $3 \mathrm{~h}$ under an autogenous pressure (ca. $\left.32 \mathrm{bar}\right), 2.5 \mathrm{~g} \mathrm{CJO}(2.89 \mathrm{mmol}), 10 \mathrm{~g} \mathrm{MeOH}(313 \mathrm{mmol}), 0.375$ g catalyst.

b The reaction period and catalyst amount are increased to $5 \mathrm{~h}$ and $30 \mathrm{wt} \%$ of CJO, respectively. 


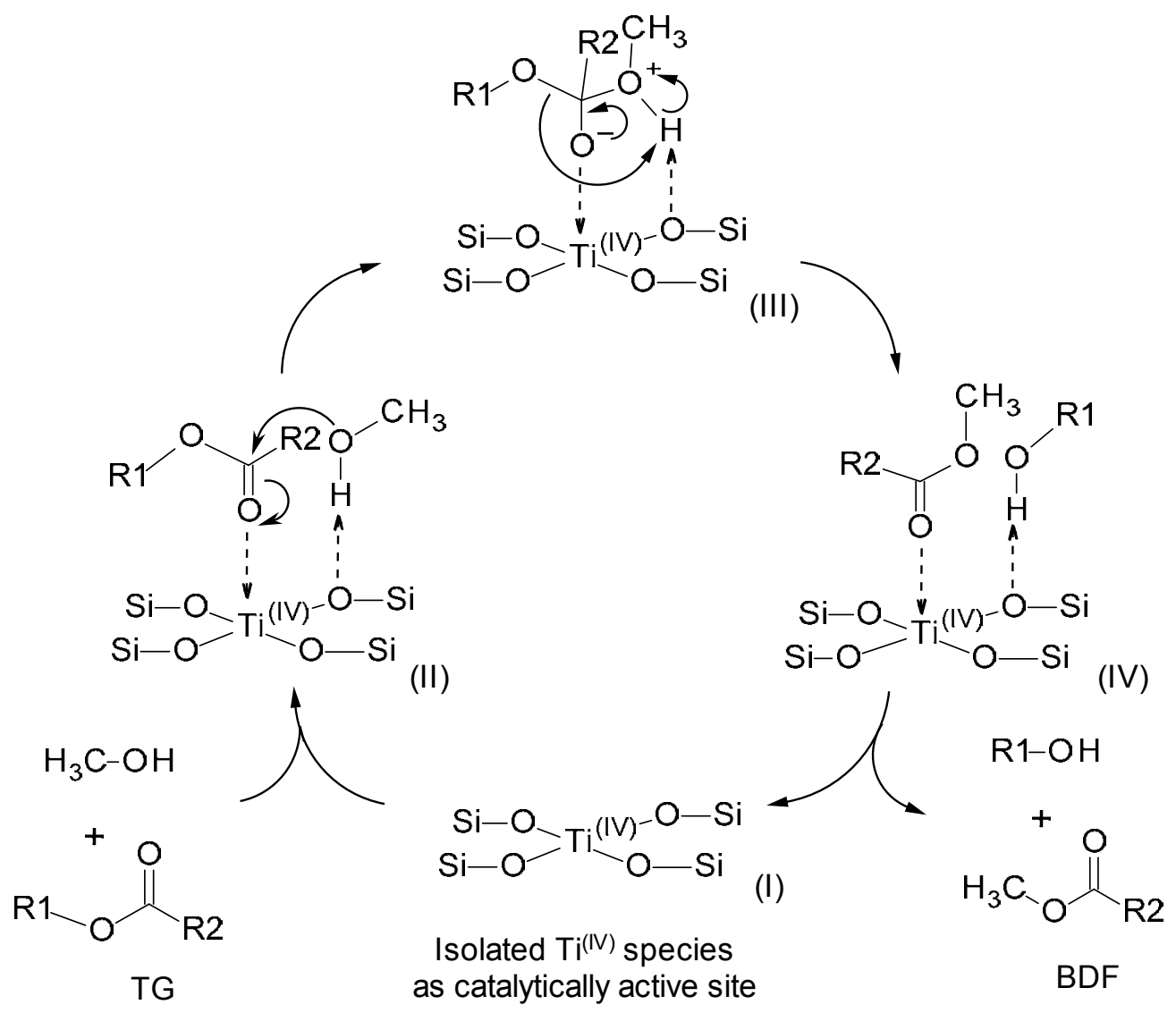

Scheme 1. Proposed reaction mechanism of high-quality BDF synthesis over Ti-SBA-15 catalyst. 

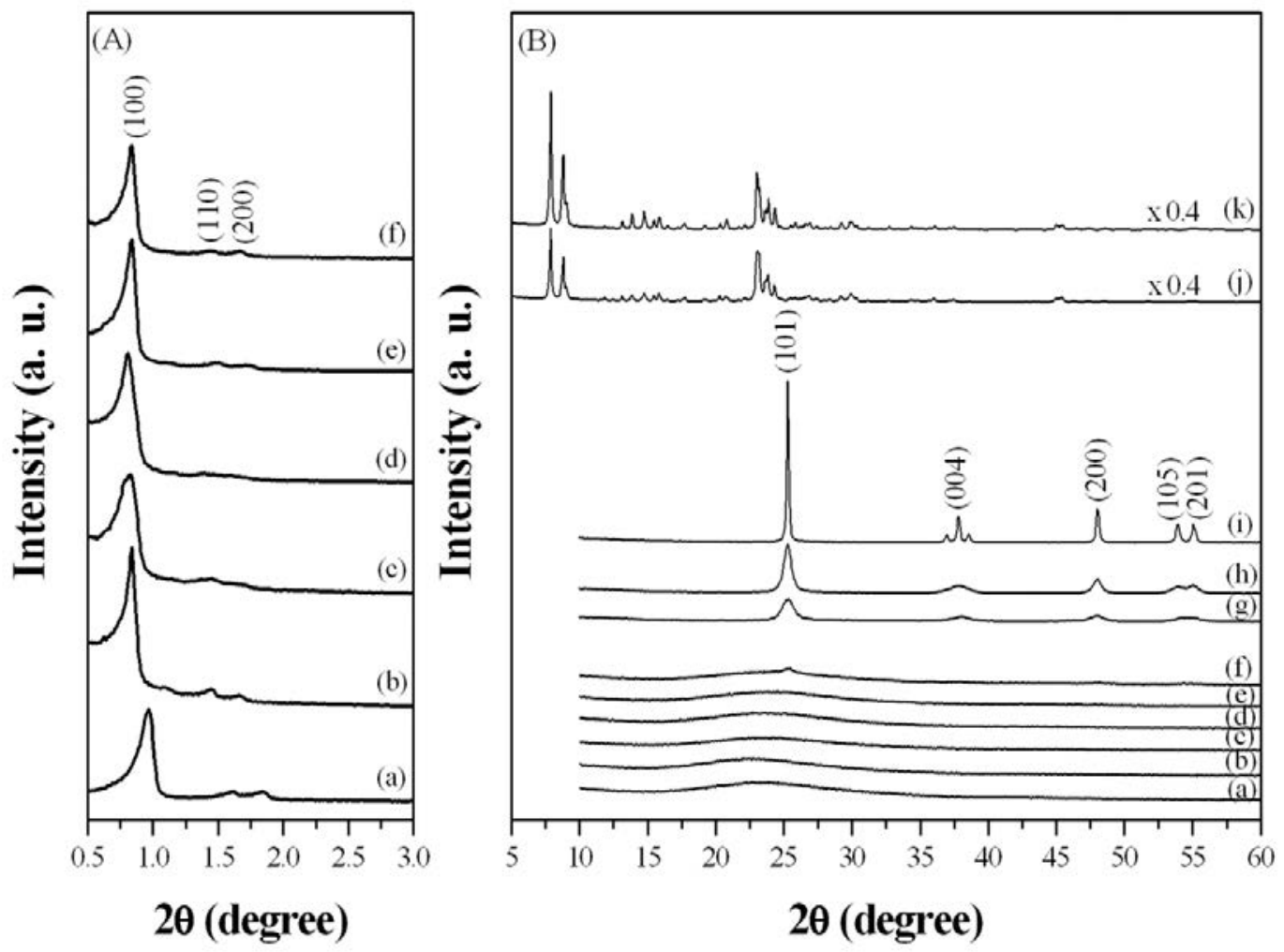

Fig. 1. (A) Small- and (B) wide-angle XRD patterns of (a) siliceous SBA-15, (b) 1Ti-SBA-15, (c) 3Ti-SBA-15, (d) 5Ti-SBA-15, (e) 7Ti-SBA-15, (f) 10Ti-SBA-15, (g) $\mathrm{TiO}_{2}-\mathrm{S}$, (h) $\mathrm{TiO}_{2}-\mathrm{M}$, (i) $\mathrm{TiO}_{2}-\mathrm{L}$, (j) H-ZSM-5 and (k) TS-1 catalysts. 

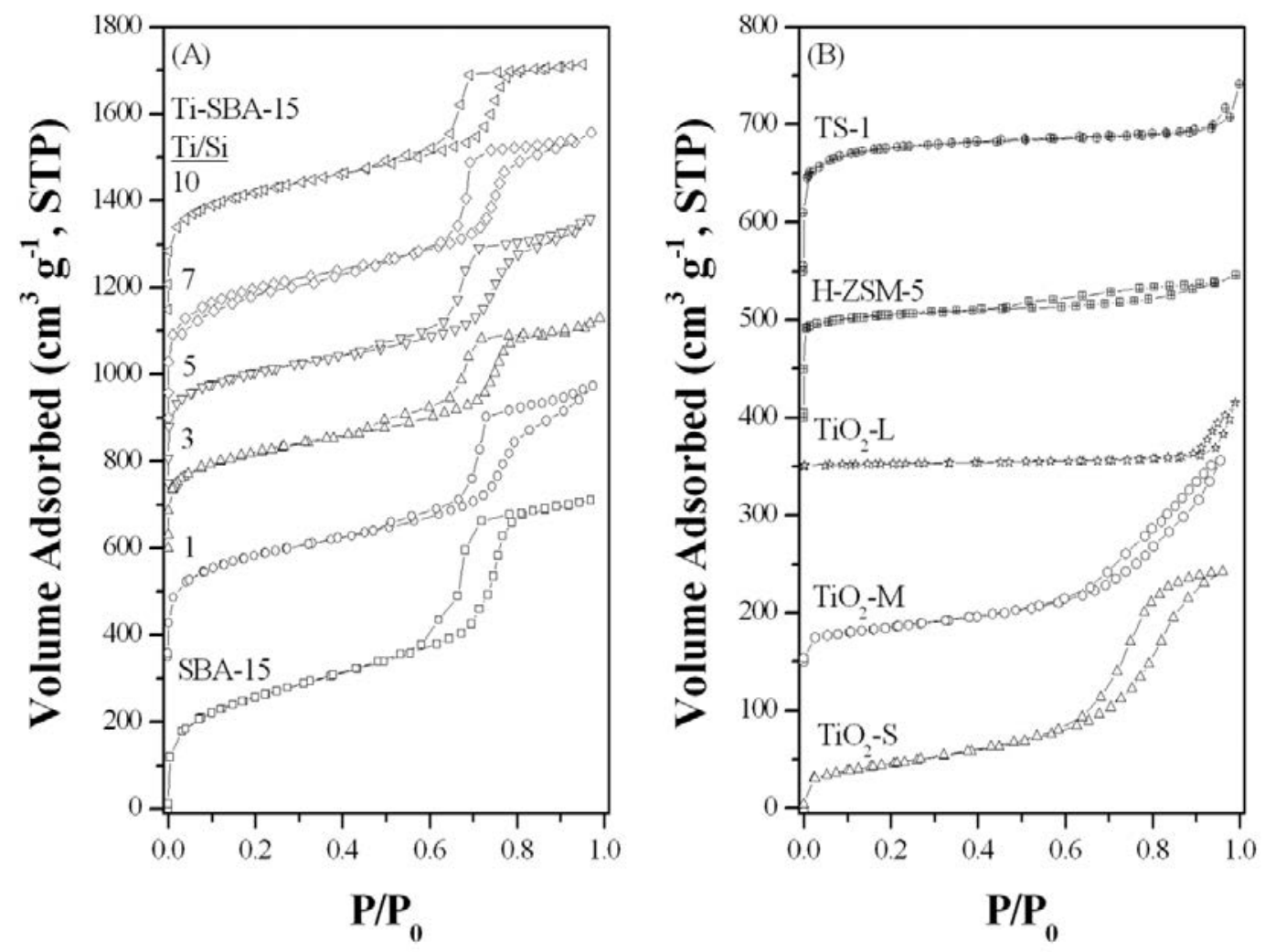

Figure 2. $\mathrm{N}_{2}$ adsorption-desorption isotherms of (A) siliceous SBA-15 and Ti-SBA-15 catalysts, and (B) $\mathrm{TiO}_{2}-\mathrm{S}, \mathrm{TiO}_{2}-\mathrm{M}, \mathrm{TiO}_{2}-\mathrm{L}, \mathrm{H}-\mathrm{ZSM}-5$ and TS-1 catalysts. 

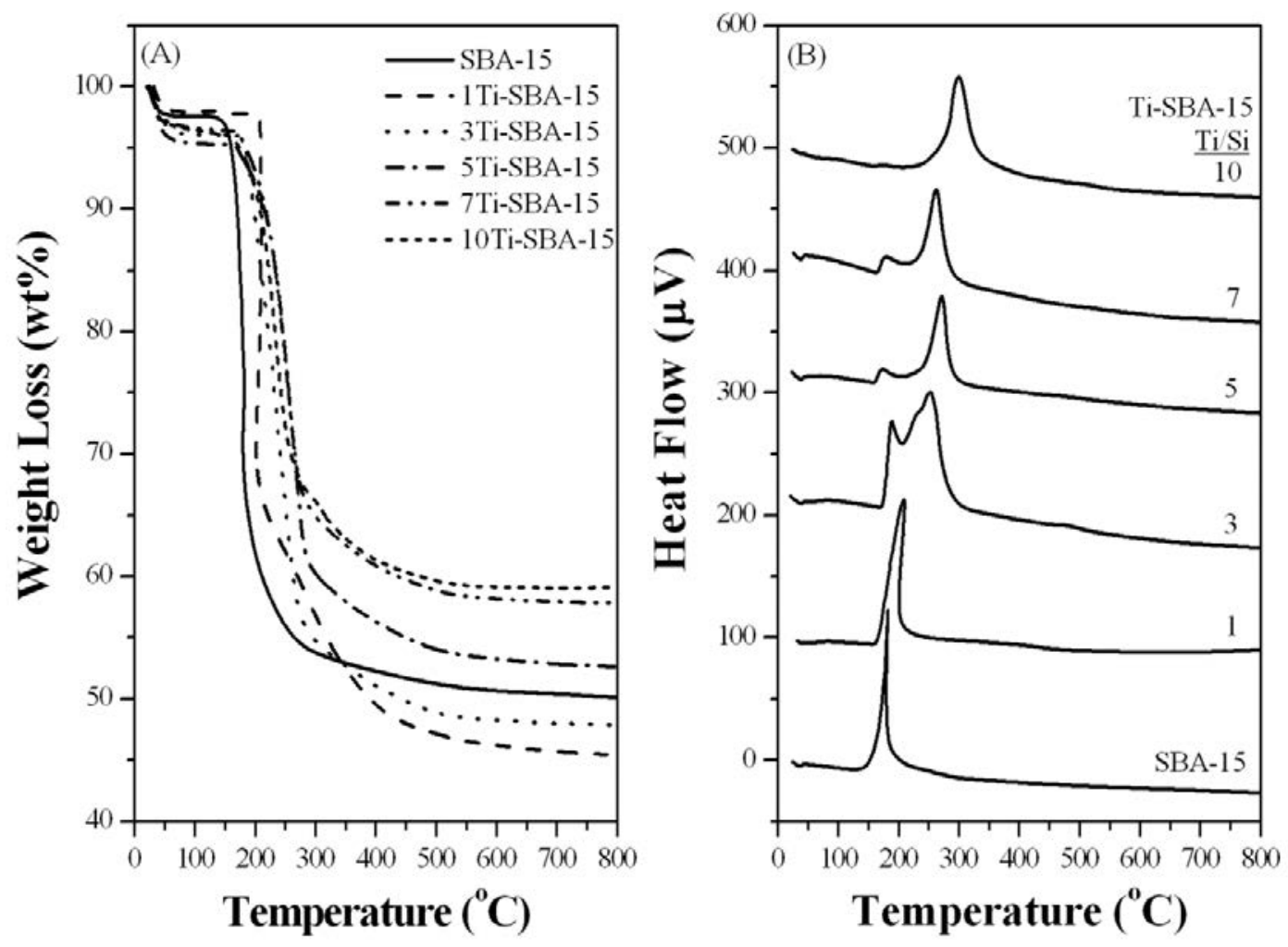

Figure 3. (A) TGA and (B) DTA profiles of as-made siliceous SBA-15 and Ti-SBA-15 catalysts. 

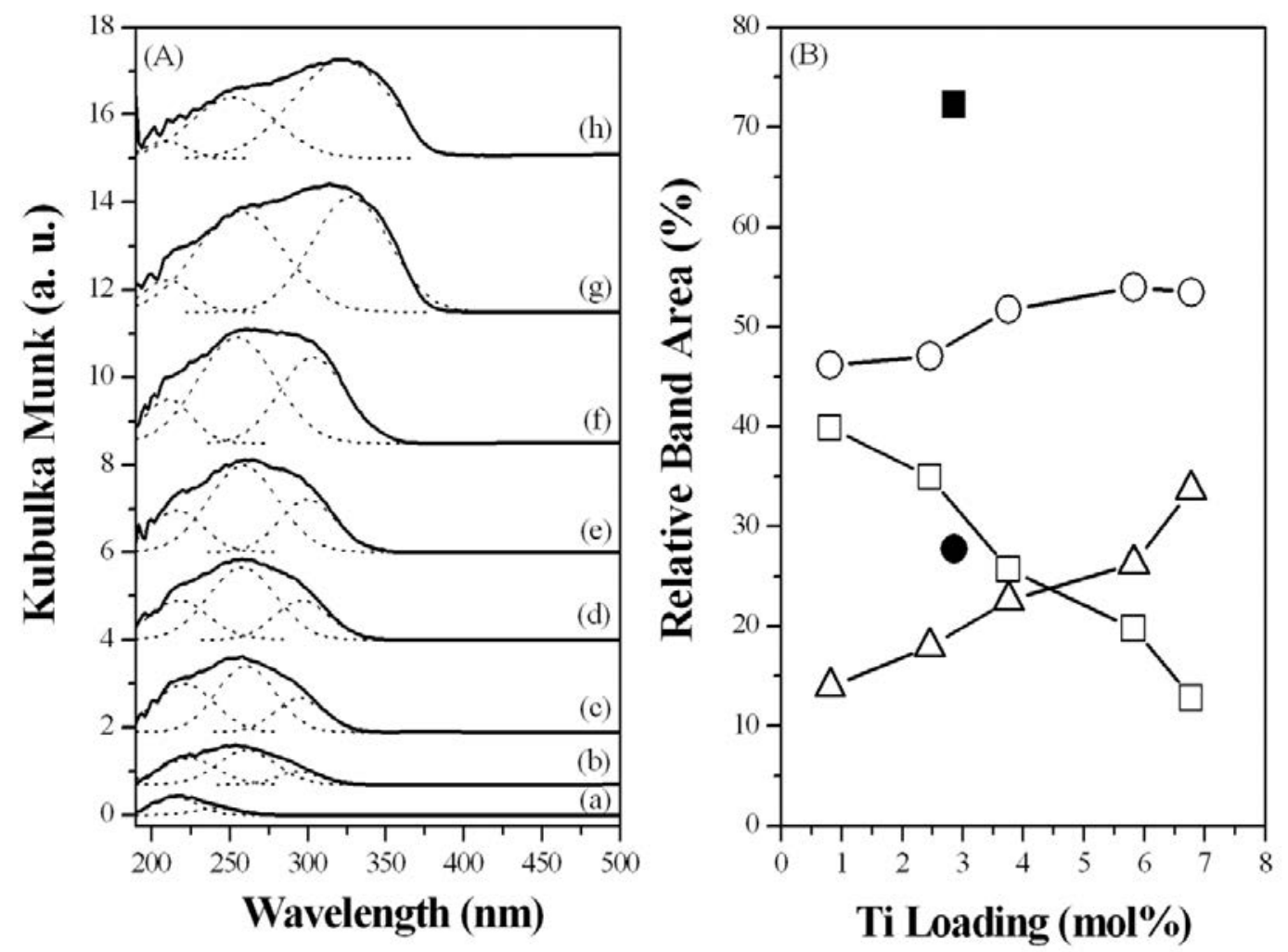

Figure 4. (A) DR UV-Vis spectra of (a) TS-1, (b) 1Ti-SBA-15, (c) 3Ti-SBA-15, (d) 5Ti-SBA-15, (e) 7Ti-SBA-15, (f) 10Ti-SBA-15, (g) $\mathrm{TiO}_{2}-\mathrm{S}$ and (h) $\mathrm{TiO}_{2}-\mathrm{L}$ catalysts, and (B) the relative peak areas of ( $\square$ and $\mathbf{m}) \mathrm{O}^{2-}$ to tetrahedral $\mathrm{Ti}^{4+}$ LMCT band, ( $\mathrm{O}$ and -) $\mathrm{O}^{2-}$ to octahedral $\mathrm{Ti}^{4+}$ LMCT band and $(\triangle)$ band gap transition in Ti-SBA-15 (open symbol) and TS-1 (solid symbol) catalysts. 

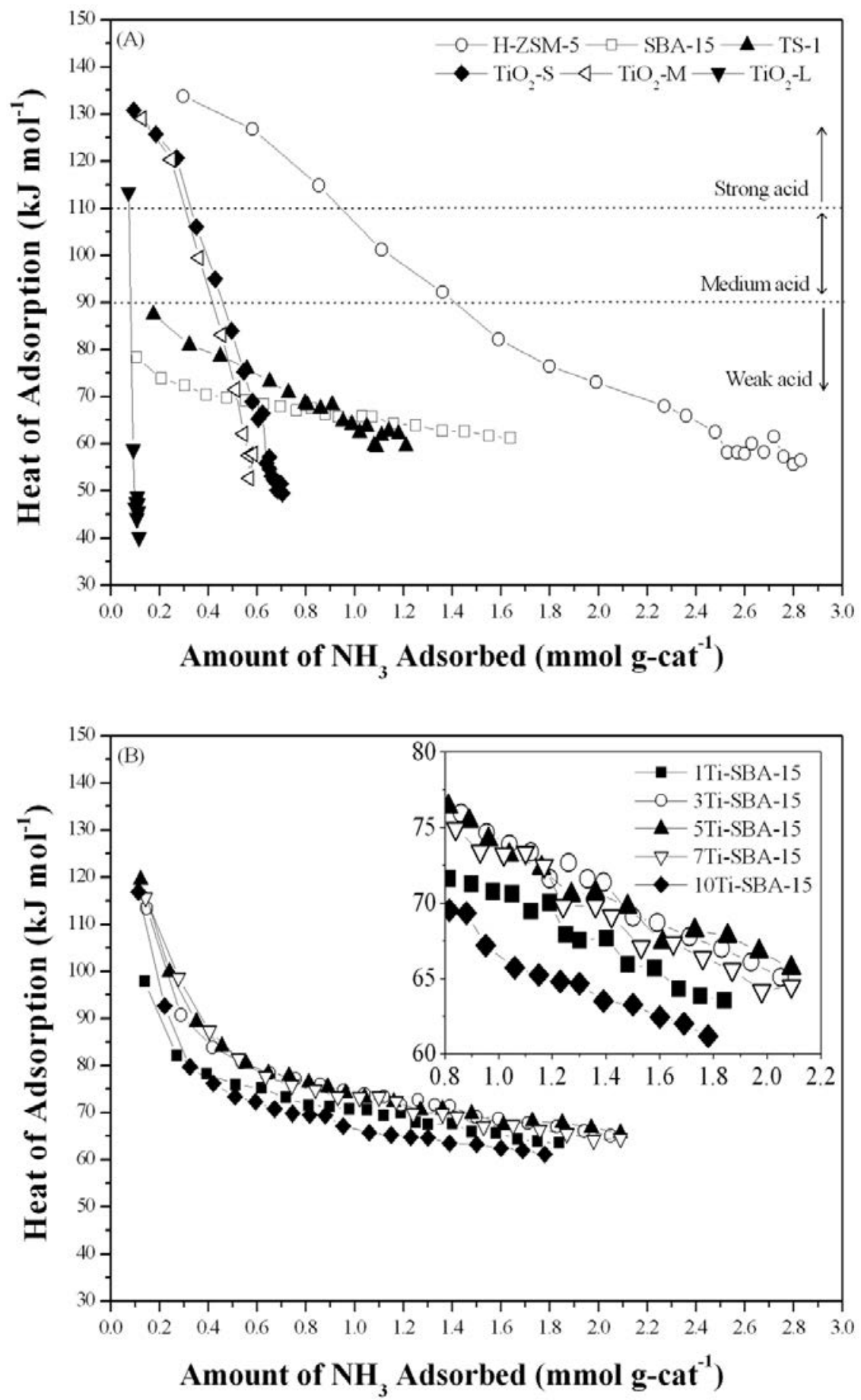

Figure 5. Differential heat of $\mathrm{NH}_{3}$ adsorbed on (A) reference catalysts and (B) Ti-SBA-15 catalysts with various Ti loadings at $50{ }^{\circ} \mathrm{C}$. 

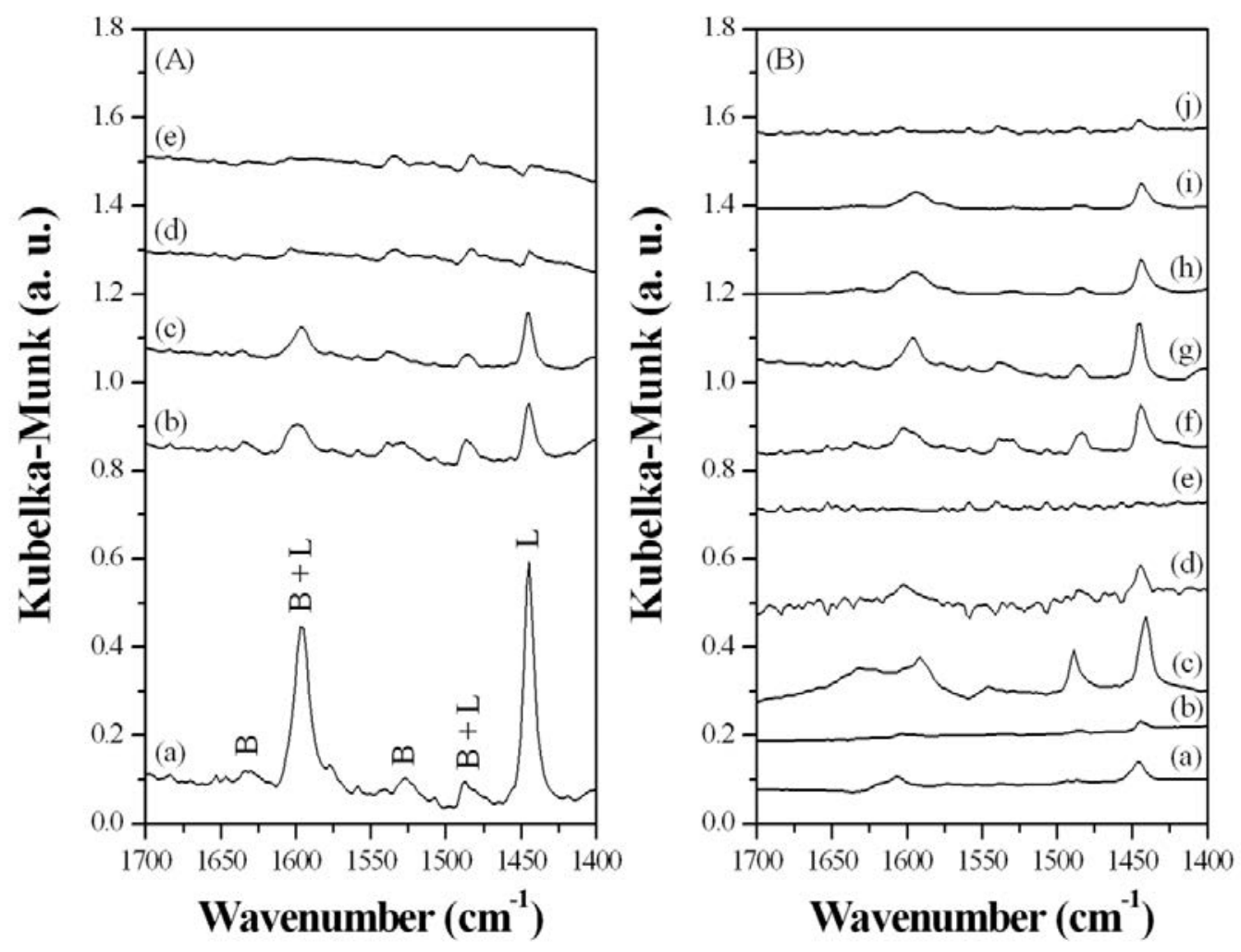

Figure 6. (A) DRIFT spectra of pyridine adsorbed on 3Ti-SBA-15 catalyst recorded at different temperatures of (a) $100{ }^{\circ} \mathrm{C}$, (b) $150{ }^{\circ} \mathrm{C}$, (c) $200{ }^{\circ} \mathrm{C}$, (d) $300{ }^{\circ} \mathrm{C}$ and (e) $400{ }^{\circ} \mathrm{C}$, and (B) DRIFT spectra of pyridine adsorbed on (a) $\mathrm{TiO}_{2}-\mathrm{S}$, (b) $\mathrm{TiO}_{2}-\mathrm{L}$, (c) $\mathrm{H}-\mathrm{ZSM}-5$, (d) TS-1, (e) SBA-15, (f) 1Ti-SBA-15, (g) 3Ti-SBA-15, (h) 5Ti-SBA-15, (i) 7Ti-SBA-15 and (j) 10Ti-SBA-15, recorded at $200{ }^{\circ} \mathrm{C}$. 


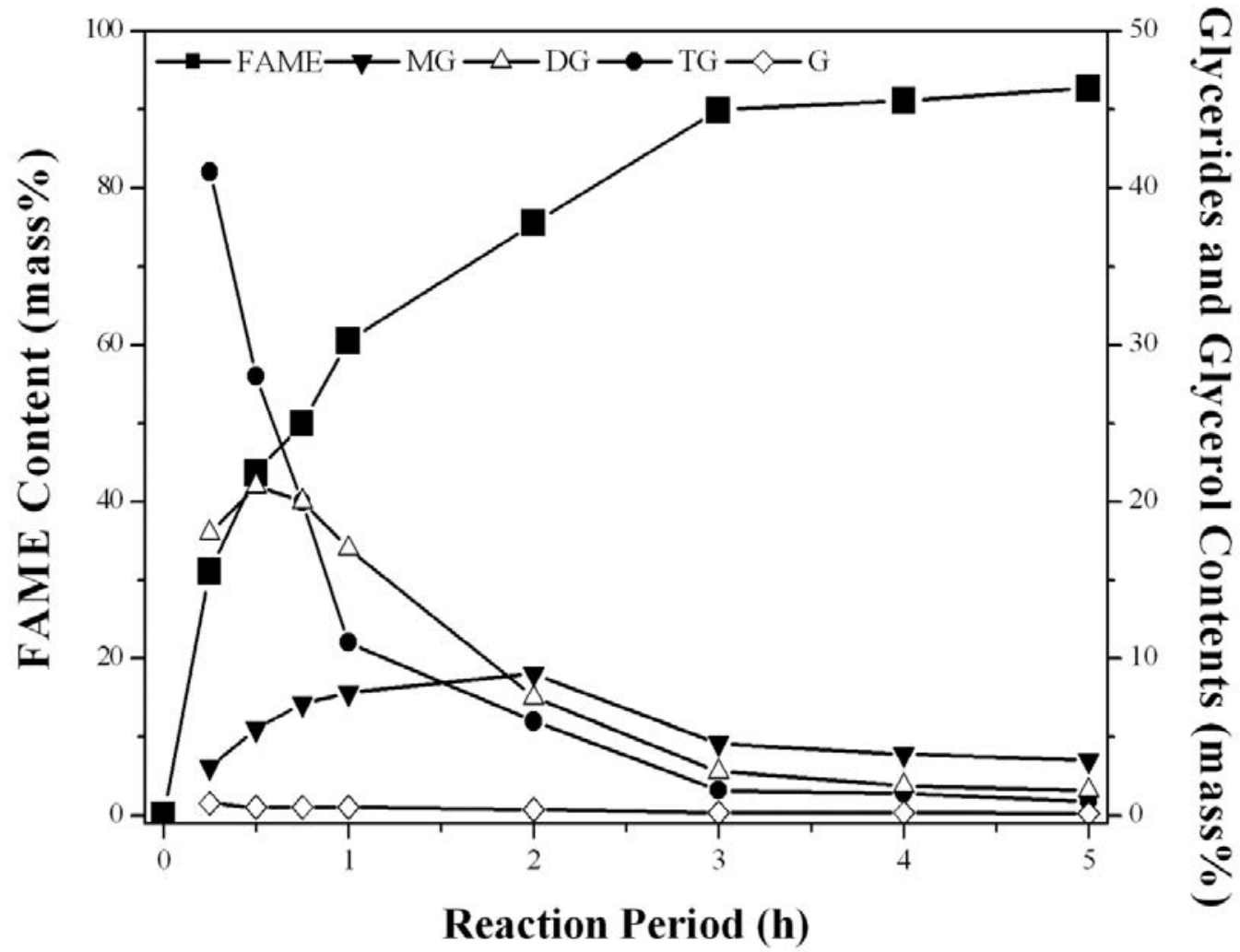

Figure 7. Transesterification of $\mathrm{CJO}$ with methanol as a function of period over 3Ti-SBA- 15 catalyst at $200{ }^{\circ} \mathrm{C}$. 


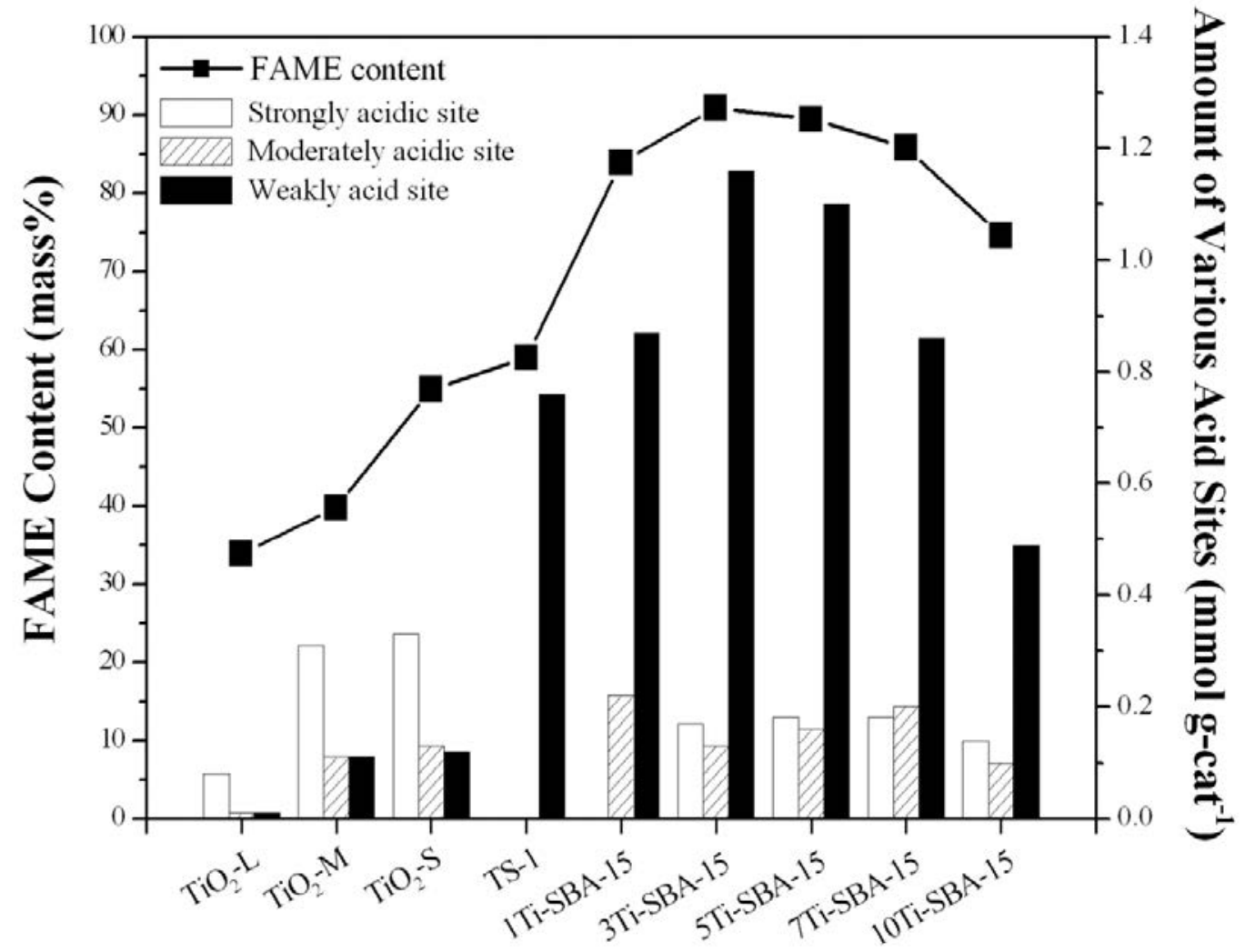

Figure 8. The correlation of FAME content with the amounts of strongly, moderately and weakly acidic sites in various Ti-containing catalysts. 


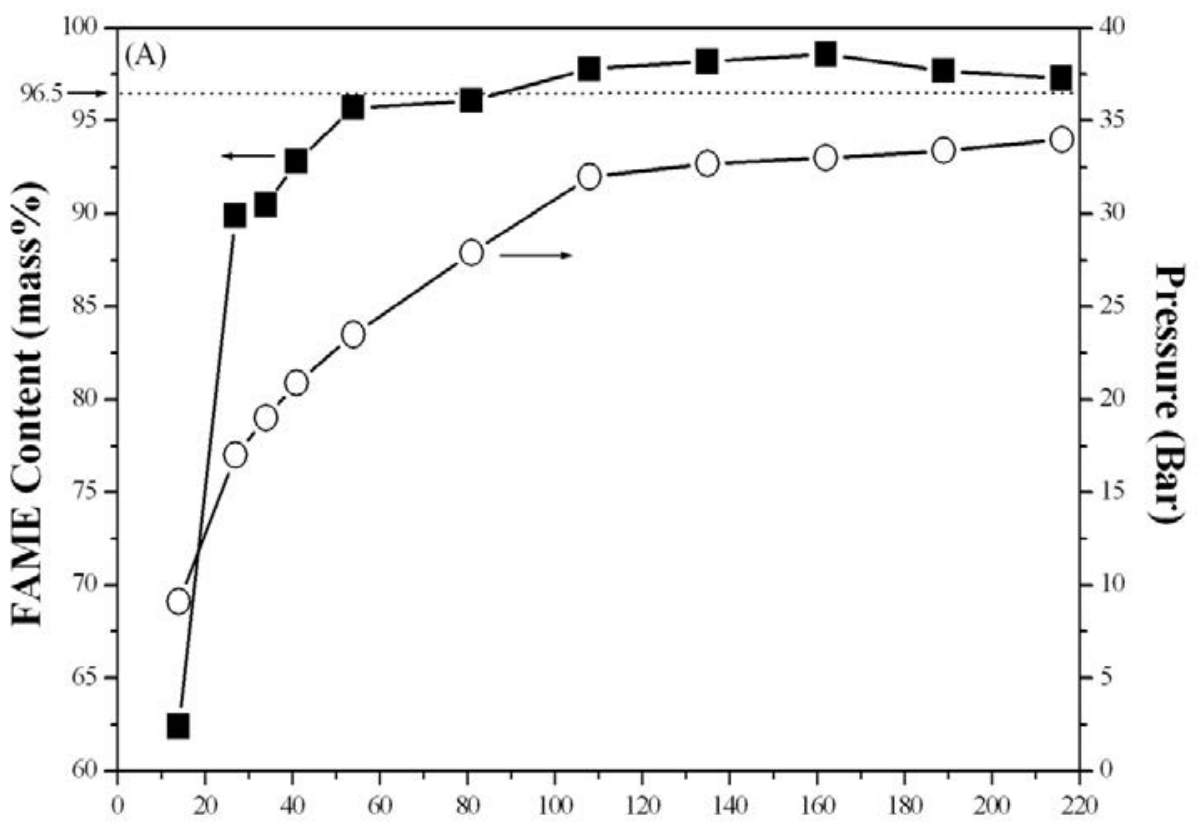

MeOH-to-Oil Molar Ratio

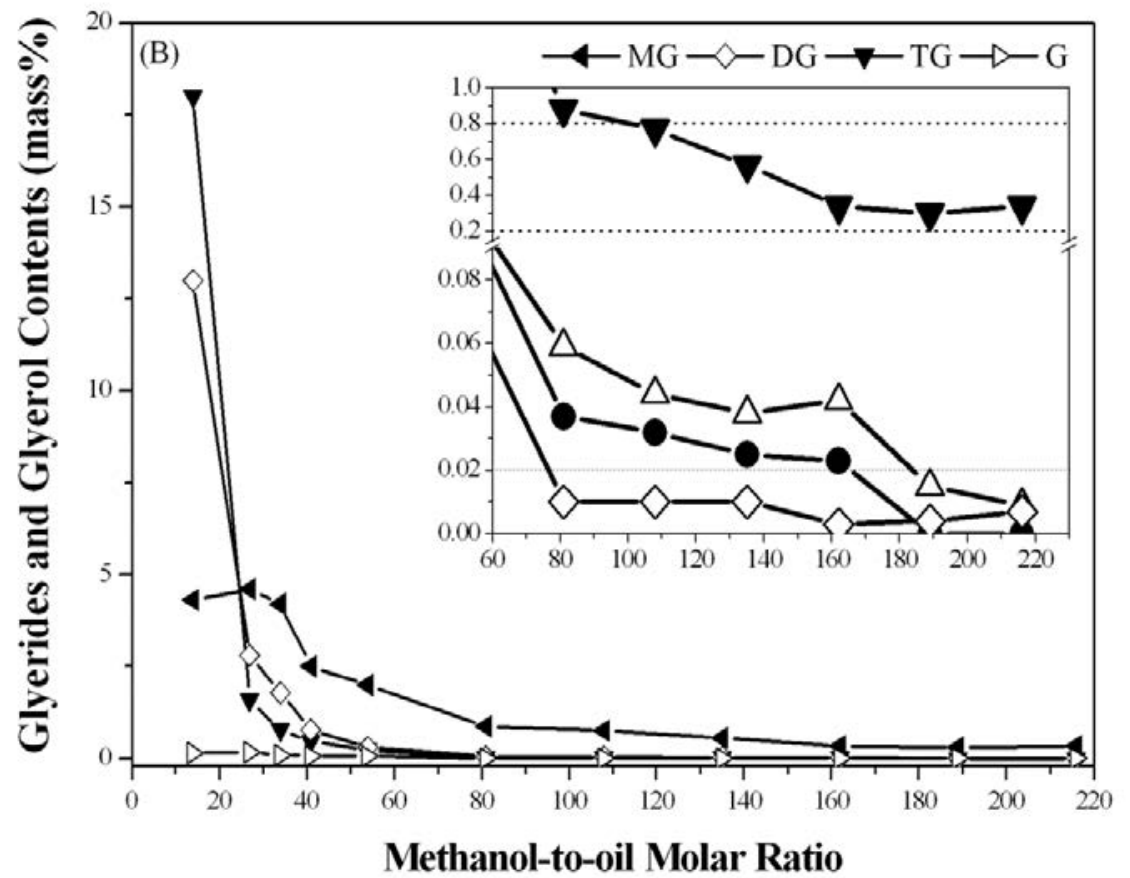

Figure 9. Effect of methanol-to-oil molar ratio on the reaction pressure and the compositions of Jatropha BDF products over 3Ti-SBA-15 catalyst at $200{ }^{\circ} \mathrm{C}$ for $3 \mathrm{~h}$. 
Graphical Abstract to Applied Catalysis B: Environmental

\section{Simultaneous Esterification/Transesterification over Innovative Ti-SBA-15 Solid Acid}

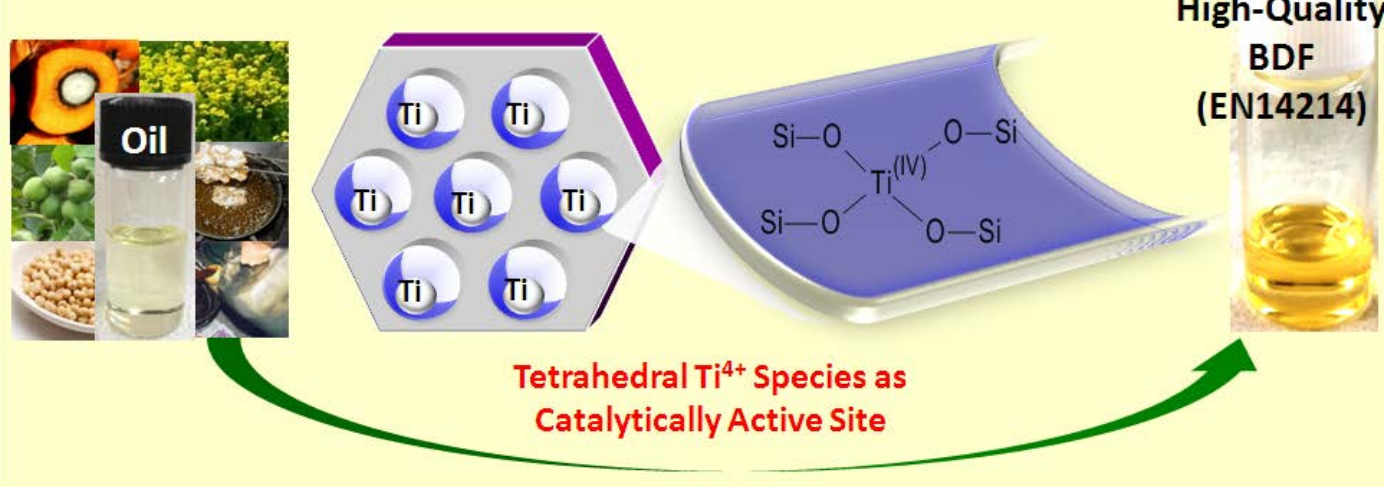

Ti-incorporated SBA-15 mesoporous silica was an efficient Lewis solid acid catalyst with high water and FFA tolerance levels for the production of high-quality BDFs derived from a great diversity of vegetable oils at $200{ }^{\circ} \mathrm{C}$ under autogeneous pressure. 